\title{
Dietary lipid and n-3 LC-PUFA levels impact growth performance and lipid metabolism of juvenile mud crab, Scylla paramamosain
}

Xuexi Wang ${ }^{1}$, Min $\mathrm{Jin}^{1}{ }^{*}$, Xin Cheng ${ }^{1}$, Jiaxiang Luo ${ }^{1}$, Lefei Jiao ${ }^{1}$, Mónica B. Betancor ${ }^{2}$, Douglas R. Tocher ${ }^{2}$, Qicun Zhou ${ }^{1} *$

${ }^{1}$ Laboratory of Fish and Shellfish Nutrition, School of Marine Sciences, Ningbo University, Ningbo 315211, China

${ }^{2}$ Institute of Aquaculture, Faculty of Natural Sciences, University of Stirling, Stirling FK9 4LA, United Kingdom

* Corresponding author:

E-mail address:

jinmin@nbu.edu.cn (M. Jin); zhouqicun@nbu.edu.cn (Q. -C. Zhou)

Abbreviations: WG, weight gain; SGR, specific growth rate; MF, molting frequence; ELOVL4, elongase of very long-chain fatty acids 4; $\triangle 6 \mathrm{FAD}$, delta-6 fatty acyl desaturase; SREBP-1, sterol regulatory element binding protein-1; FAS, fatty acid synthase; G6PD, glucose-6-phosphate dehydrogenase; 6PGD, 6-phosphogluconate dehydrogenase; CPT, carnitine palmitoyltransferase; ACO, acyl-CoA oxidase; HSL, hormone-sensitive triglyceride lipase; EF1- $\alpha$, elongation factor $1-\alpha$.

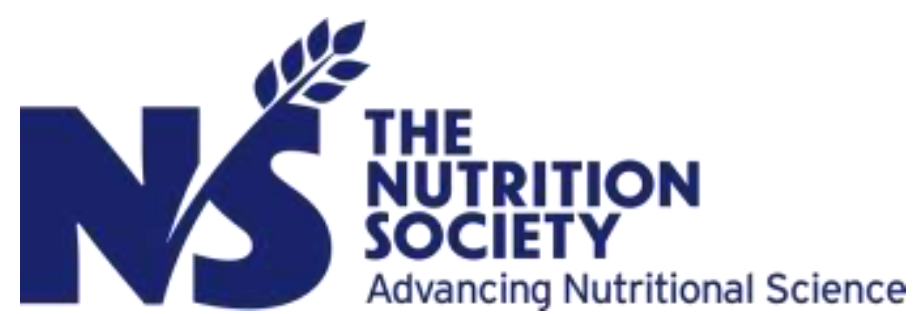

This peer-reviewed article has been accepted for publication but not yet copyedited or typeset, and so may be subject to change during the production process. The article is considered published and may be cited using its DOI

10.1017/S0007114520003335. This version is published under a Creative Commons CC-BY-NCND. No commercial re-distribution or re-use allowed. Derivative works cannot be distributed. The British Journal of Nutrition is published by Cambridge University Press on behalf of The Nutrition Society 


\section{Accepted manuscript}

\section{Abstract}

An 8 weeks feeding trial was conducted to evaluate the effects of dietary n-3 LC-PUFA levels on growth performance, tissue fatty acid profiles and relative expression of genes involved in lipid metabolism of mud crab (Scylla paramamosain). Ten isonitrogenous diets were formulated to contain five n-3 LC-PUFA levels at $7 \%$ and $12 \%$ dietary lipid levels. Highest weight gain and specific growth rate were observed in crabs fed the diets with 19.8 and $13.2 \mathrm{mg} \mathrm{g}^{-1} \mathrm{n}-3$ LC-PUFA at $7 \%$ and $12 \%$ lipid, respectively. Moisture and lipid contents in hepatopancreas and muscle were significantly influenced by dietary n-3 LC-PUFA at the two lipid levels. The DHA, EPA, n-3 LC-PUFA contents and n-3/n-6 PUFA ratio in hepatopancreas and muscle significantly increased as dietary n-3 LC-PUFA levels increased at both lipid levels. The expression levels of $\Delta 6$ FAD and ACO in hepatopancreas increased significantly, and expression levels of FAS, CPTI and HSL were down-regulated, with increased dietary n-3 LC-PUFA regardless of lipid level. Based on weight gain, the n-3 LC-PUFA requirements of $S$. paramamosain were estimated to be $20.1 \mathrm{mg} \mathrm{g}^{-1}$ and $12.7 \mathrm{mg} \mathrm{g}^{-1}$ of diet at $7 \%$ and $12 \%$ dietary lipid, respectively. Over all, dietary lipid level influenced lipid metabolism, and purified, high-lipid diets rich in palmitic acid reduced the n-3 LC-PUFA requirement of juvenile mud crab.

Keywords: n-3 LC-PUFA; Growth; LC-PUFA biosynthesis; Lipid metabolism; Scylla paramamosain 


\section{Introduction}

It is accepted that marine fish and crustacean are generally unable to synthesize n-3 and n-6 long-chain polyunsaturated fatty acids (LC-PUFA) from their respective precursors, linolenic acid (LNA, 18:3n-3) and linoleic acid (LA, 18:2n-6) ${ }^{(1)}$. Therefore, LC-PUFA such as eicosapentaenoic acid (EPA, 20:5n-3), docosahexaenoic acid (DHA, 22:6n-3) and arachidonic acid (ARA, 20:4n-6) are considered as essential fatty acids (EFA) for marine fish and crustacean. Numerous studies have demonstrated that DHA, EPA and ARA play important roles in survival and growth of marine fish and crustacean larvae ${ }^{(2)}$, and dietary deficiencies result in reduced survival, poor growth and prolonged inter-molt periods of crustaceans $^{(3)}$. However, it was also reported that excessive dietary LC-PUFA levels could result in growth depression $^{(4)}$. The EFA must be included in the diet at adequate levels to fulfill requirements for growth, survival and development ${ }^{(5)}$. Moreover, fish oil remains the main but limited source of EFA, especially n-3 LC-PUFA, in aquafeeds ${ }^{(6)}$. Hence, it is important to determine the optimal dietary n-3 LC-PUFA requirements of marine fish and crustaceans.

The n-3 LC-PUFA requirements have been studied for several crustacean species. In swimming crab (Portunus trituberculatus) (initial weight 200 - $300 \mathrm{~g}$ ) at the stage of ovarian development, optimal dietary n-3 LC-PUFA level was $6.0-8.0 \mathrm{mg} \mathrm{g}^{-1}$ of dry diet with a DHA/EPA ratio of $2.0^{(7-8)}$, and a suitable supplement of ARA was $0.6-2.4 \mathrm{mg} \mathrm{g}^{-1}$ of $\operatorname{diet}^{(9)}$. Other studies showed that the optimum dietary n-3 LC-PUFA requirements for P. trituberculatus (initial weight $2.17 \mathrm{~g}$ and $24.00 \mathrm{~g}$ ) were 23.5 $\mathrm{mg} \mathrm{g}^{-1}$ and $23.3 \mathrm{mg} \mathrm{g}^{-1}$ of diet when DHA/EPA ratios were 0.9 and 1.1 , respectively ${ }^{(10-11)}$. The optimal n-3 LC-PUFA requirement was $5.0 \mathrm{mg} \mathrm{g}^{-1}$ and $8.9 \mathrm{mg} \mathrm{g}^{-1}$ of diet for juvenile Pacific white shrimp (Litopenaeus vannamei) (initial weight $1.43 \mathrm{~g}$ and $0.50 \mathrm{~g})^{(4,12)}$, respectively. It was also demonstrated that the optimum n-3 LC-PUFA requirements were higher in subadult than adult L. vannamei ${ }^{(13)}$. Therefore, previous studies have revealed that quantitative EFA requirements may vary with culture species, stage of development, dietary ingredients, and with dietary LC-PUFA (DHA/EPA ratio) ${ }^{(5)}$. Many investigations of n-3 LC-PUFA requirements for marine fish or crustacean used diets based on fishmeal and/or fish oil where the natural occurrence of n-3 LC-PUFA in these marine ingredients strongly influences the proportions of dietary fatty acids. Thus, purified or semi-purified artificial diets are required to properly evaluate n-3 LC-PUFA requirements. Previous studies also demonstrated that n-3 LC-PUFA requirements may also be affected by dietary lipid level ${ }^{(14)}$. For example, n-3 LC-PUFA requirement increased from $12.0-22.0 \mathrm{mg} \mathrm{g}^{-1}$ to $27.0-32.0 \mathrm{mg} \mathrm{g}^{-1}$ of dry weight when dietary lipid level increased from $10 \%$ to $15 \%$ in red sea bream (Pagrosomus major) ${ }^{(15)}$. The n-3 LC-PUFA 
requirement of red drum (Sciaenops ocellatus) did not exceed $3.8 \mathrm{mg} \mathrm{g}^{-1}$ of diet when dietary lipid levels was $7.4 \%$, while the optimal n-3 LC-PUFA level ranged from $28.7 \mathrm{mg} \mathrm{g}^{-1}$ to $51.2 \mathrm{mg} \mathrm{g}^{-1}$ of diet when dietary lipid level was $18.3 \%^{(16-17)}$. Hence, in order to determine the $n-3$ LC-PUFA requirement of marine crustaceans, purified diets must be used, and dietary lipid level and the ratio of dietary LC-PUFA must also be considered. However, studies on the relationship between these factors and dietary LC-PUFA requirement are few. Whether there was a relationship in crustaceans between dietary lipid level and n-3 LC-PUFA requirement existed was unknown, and how dietary lipid level affects n-3 LC-PUFA requirement of crustaceans was not clear.

The mud crab is distributed widely throughout the Indian ocean and Indo-Pacific regions, and is a commercially important marine crab species due to its short growth cycle, high adaptability and nutritional value ${ }^{(18)}$. In China, S. paramamosain has become major marine aquaculture crustaceans in recent years, and the culture technology and techniques have constantly improved ${ }^{(18)}$. In 2018, the yield of farmed mud crabs (mainly S. paramamosain) reached 157,712 tons ${ }^{(19)}$. However, the development of commercial feed for S. paramamosain has lagged in the crab farming industry and there are few reports on the nutritional requirements of mud $\mathrm{crab}^{(20-23)}$ although dietary lipid levels of $8.52 \%-11.63 \%$ (optimum $9.50 \%$ ) could maintain growth performance ${ }^{(20)}$. The requirement for dietary LC-PUFA in swimming crab was supposed to range from $6.0-23.6 \mathrm{mg} \mathrm{g}^{-1}$ of $\operatorname{diets}^{(7-8,10-11)}$, and the optimum dietary DHA/EPA ratio for juvenile crab was about 1.0. However, no information was available concerning n-3 LC-PUFA requirements of $S$. paramamosain. Hence, the objective of the present study was to determine the optimal n-3 LC-PUFA requirement at two dietary lipid levels, and to evaluate n-3 LC-PUFA supplementation on growth performance, tissue fatty acid profiles and expression levels of genes related to fatty acid biosynthesis and lipid metabolism in S. paramamosain.

\section{Methods}

\section{Ethics statement}

The present study was performed in strict accordance with the Standard Operation Procedures of the Guide for Use of Experimental Animals of Ningbo University. The experimental protocol and procedures were approved by the Institutional Animal Care and Use Committee of Ningbo University. 


\section{Diet preparation}

Ten isonitrogenous purified diets ( 45 \% crude protein) were formulated with 0 (control), $0.75 \%$, $1.50 \%, 2.25 \%$ and $3.00 \%$ n-3 LC-PUFA (DHA: EPA ratio 1:1) at two dietary lipid levels of $7 \%$ and $12 \%$. The analyzed n-3 LC-PUFA values were $0.15,7.4,14.8,19.8$ and $24.9 \mathrm{mg} \mathrm{g}^{-1}$ at $7 \%$ lipid, and $0.10,6.8,13.2,19.0$ and $25.6 \mathrm{mg} \mathrm{g}^{-1}$ at $12 \%$ lipid, respectively. Casein and soy protein concentrate were used as protein sources, and semi-pure DHA, EPA, ARA, palmitic acid and soy lecithin were used as lipid sources (Table 1), with palmitic acid used to alter and balance dietary $7 \%$ and $12 \%$ lipid levels without impacting LC-PUFA levels or metabolism. ARA and cholesterol were supplemented to maintain normal growth and molting according to data from P. trituberculatus and Scylla serrata ${ }^{(9,24)}$. The fatty acid profiles of the experimental diets were presented as $\mathrm{mg} \mathrm{g}^{-1}$ in Table 2. All the ingredients were purchased from Ningbo Tech-Bank Feed Co. Ltd. and ground into fine powder with particle size less than $177 \mu \mathrm{m}$. The micro-components, such as vitamin and mineral premixes, were then mixed using the progressive enlargement method. EPA, DHA, palmitic acid, soybean lecithin and distilled water (400 $\left.\mathrm{g} \mathrm{kg}^{-1}\right)$ were then added to the premixed dry ingredients and mixed until homogenous in a Hobart-type mixer. Cold-extruded pellets were produced (F-26, machine factory of South China University of Technology, Guangzhou, China), and the pellet strands cut into uniform pellet sizes (two pellet sizes: $2.0 \mathrm{~mm}$ diameter, $4.0 \mathrm{~mm}$ length; $4 \mathrm{~mm}$ diameter, $6.0 \mathrm{~mm}$ length) using a granulating machine (G-250, machine factory of South China University of Technology, Guangzhou, China), steamed for $30 \mathrm{~min}$ at $90{ }^{\circ} \mathrm{C}$, and then air-dried to approximately $10 \%$ moisture. The dried diets were sealed in vacuum-packed bags and stored at $-20{ }^{\circ} \mathrm{C}$ until used.

\section{Experimental crabs and feeding trial}

Juvenile mud crabs were obtained from Jia-Shun Aquatic Cooperatives (Taizhou, China). Before the experiment, the crabs were acclimated in a cement pool and fed a commercial feed (45\% crude protein, $8 \%$ crude lipid; Ningbo Tech-Bank Corp., Ningbo, China) for 2 weeks. There were three replicates (15 crabs per replicate) for each diet treatment. At the beginning of feeding trial, a total of 450 juvenile crabs $\left(30.55 \pm 0.75 \mathrm{~g} \mathrm{crab}^{-1}\right)$ were then randomly allocated to individual cellular systems (each cell, $0.33 \mathrm{~m} \times 0.23 \mathrm{~m} \times 0.15 \mathrm{~m}$, length $\times$ width $\times$ height; Supplementary Figure 1) ${ }^{(18,20)}$. Each cell was half filled with a continuous flow of seawater $\left(300 \mathrm{~mL} \mathrm{~min}^{-1}\right)$ and crabs were fed once daily at 18:00 to apparent satiation with $6 \%-8 \%$ of wet body weight during the feeding duration ${ }^{(26)}$. Faeces and 


\section{Accepted manuscript}

uneaten feed from each cell were removed daily. Any dead crabs were taken out and weighed as soon as being observed, and the number of molts were calculated and recorded daily.

During the experimental period, the temperature of flowing water in the crab cells was $26-32{ }^{\circ} \mathrm{C}$, salinity was approximately $26-28 \mathrm{~g} \mathrm{~L}^{-1}$, $\mathrm{pH}$ was 7.7 - 8.0, the ammonia nitrogen was lower than 0.05 $\mathrm{mg} \mathrm{L}^{-1}$, and dissolved oxygen was $6.5-7.0 \mathrm{mg} \mathrm{L}^{-1}$. Salinity, $\mathrm{pH}$, ammonia nitrogen and dissolved oxygen in the cellular systems were measured by the YSI Pro plus (YSI, Yellow Springs, Ohio, USA). The feeding trial lasted for 8 weeks.

\section{Sample collection}

At the beginning of the feeding trial, 10 juvenile mud crabs were randomly culled and stored at $-20{ }^{\circ} \mathrm{C}$ as the initial samples. At the end of trial, crabs were starved for $24 \mathrm{~h}$, and then counted and weighed to determine weight gain (WG), specific growth rate (SGR) and molting frequency (MF), which were calculated per replicate. In each replicate, hemolymph samples from three to five crabs were taken from the pericardial cavity using a $2 \mathrm{~mL}$ syringe, placed in $1.5 \mathrm{~mL}$ microfuge tubes and centrifuged at $956 \mathrm{~g}$ for $10 \mathrm{~min}$ at $4{ }^{\circ} \mathrm{C}$ (Eppendorf centrifuge 5810R, Germany). The supernatant was collected and stored at $-80{ }^{\circ} \mathrm{C}$ until further analysis. Hepatopancreas and muscle samples were dissected from the same crabs that had blood drawn. The hepatopancreas samples were divided into two portions, one was stored at $-20{ }^{\circ} \mathrm{C}$ for proximate composition and fatty acid profile analysis (three crabs per replicate), and the other was frozen immediately in liquid nitrogen and stored at $-80{ }^{\circ} \mathrm{C}$ for gene expression analysis (three crabs per replicate). Muscle samples were stored at $-20{ }^{\circ} \mathrm{C}$ for analyzing proximate composition and fatty acid profile (three crabs per replicate). Samples collected from the same replicate were pooled prior to analysis.

\section{Biochemical analysis}

\section{Proximate composition and fatty acids}

The crude protein, crude lipid, moisture and ash content of diets, muscle and hepatopancreas of the crabs were determined according to the method of the Association of Official Analytical Chemists ${ }^{(27)}$. The moisture content was determined by drying the samples to a constant weight at $105^{\circ} \mathrm{C}$. The crude protein contents $(\mathrm{N} \times 6.25)$ were assayed by the Dumas combustion method with a protein analyzer (FP-528, LECO, USA). Crude lipid was measured via the petroleum ether extraction method using a Soxtec System HT (SX360, OPSIS, Sweden), and the ash content was determined after incineration in a muffle furnace at $550{ }^{\circ} \mathrm{C}$ for $8 \mathrm{~h}$. 


\section{Accepted manuscript}

Fatty acid compositions of diets, hepatopancreas and muscle were analyzed as described in detail previously ${ }^{(28)}$. In brief, total lipid was extracted with chloroform/methanol (2:1 by vol.) and fatty acid methyl esters (FAME) were then produced from total lipid by methanolic sulfuric acid with butylated hydroxytoluene (BHT) as antioxidant. Methyl tricosanoate (23:0; Sigma Aldridge Trading Co., Ltd., Shanghai, China) was used as internal standard at $1.0 \mathrm{mg} \mathrm{mL}^{-1}$ hexane. Gas chromatography (Agilent Technologies GC-MS 7890B-5977A, USA) was used to analysis FAME with fatty acids identified by reference to known standards and presented as percentages of area.

\section{Real-time quantitative PCR (RT-qPCR) analysis of fatty acid biosynthesis and lipid}

\section{metabolism genes in hepatopancreas}

Total RNA was extracted from hepatopancreas samples using Trizol reagent (Invitrogen, USA), the quantity and quality of total RNA assessed using a Nano DropND-1000 spectrophotometer (NanoDrop Technologies, USA) and 1.2\% denaturing agarose gel electrophoresis. The 260/280 nm absorbance ratios of all samples ranged from 1.86 to 2.00 , indicating a satisfactory purity of the RNA samples. The RNA was dissolved in $30 \mu \mathrm{L}$ Recombinant DNase I (RNase-free) (Takara, Japan) and stored at $-80{ }^{\circ} \mathrm{C}$ until use. The cDNA was synthesized for quantitative reverse-transcriptase polymerase chain reaction (qPCR) using the PrimeScript ${ }^{\mathrm{TM}}$ RT Reagent Kit (Takara, Japan) according to the manufacturer's instructions.

Elongation factor- $1 \alpha(\mathrm{EF}-1 \alpha)$ was used as a house-keeping gene after the stability of EF-1 $\alpha$ expression was confirmed. Specific primers for elongase of very long-chain fatty acids 4 (ELOVL4), delta-6 fatty acyl desaturase ( $\triangle 6 \mathrm{FAD}$ ), sterol regulatory element binding protein-1 (SREBP-1), fatty acid synthase (FAS), glucose-6-phosphate dehydrogenase (G6PD), 6-phosphogluconate dehydrogenase (6PGD), hormone-sensitive triglyceride lipase (HSL), acyl-CoA oxidase (ACO), carnitine palmitoyltransferase I and II (CPTI and CPTII) used for RT-qPCR were designed using Primer Premier 5.0 software (Supplementary Table 1). The expression of mRNA was determined by RT-qPCR (Light Cycler 96; Roche, Switzerland). The RT-qPCR was performed in a $20 \mu \mathrm{L}$ reaction volume containing $10 \mu \mathrm{L}$ of SYBR Green premix, $0.8 \mu \mathrm{L}$ of cDNA template, $0.4 \mu \mathrm{L}$ of each primer $(10 \mu \mathrm{M})$ and $8.4 \mu \mathrm{L}$ of diethyl pyrocarbonate-treated water. The RT-qPCR conditions were as follows: $95^{\circ} \mathrm{C}$ for $10 \mathrm{~min}$; 45 cycles of $95{ }^{\circ} \mathrm{C}$ for $15 \mathrm{~s}, 58{ }^{\circ} \mathrm{C}$ for $15 \mathrm{~s}$ and $72{ }^{\circ} \mathrm{C}$ for $20 \mathrm{~s}$. The data were optimized using the comparative $\mathrm{Ct}\left(2^{-\Delta \Delta \mathrm{Ct}}\right)$ value method as described by Livak and Schmittgen ${ }^{(29)}$ and then subjected to statistical analysis. 


\section{Calculations and statistical analysis}

The parameters were calculated as follows:

Weight gain $(\mathrm{WG}, \%)=100 \times\left(\mathrm{W}_{\mathrm{t}}-\mathrm{W}_{\mathrm{i}}\right) / \mathrm{W}_{\mathrm{i}}$,

Specific growth rate $\left(\mathrm{SGR}, \% \mathrm{~d}^{-1}\right)=100 \times\left(\ln _{\mathrm{t}}-\ln \mathrm{W}_{\mathrm{i}}\right) / \mathrm{t}$,

Molting frequency $(\mathrm{MF})=2 \times \mathrm{N}_{\mathrm{m}} /$ (initial number of crabs + final number of crabs)

Where $\mathrm{W}_{\mathrm{t}}$ is the final body weight $(\mathrm{g}), \mathrm{W}_{\mathrm{i}}$ is the initial body weight $(\mathrm{g})$, $\mathrm{t}$ is the experimental duration in days, $\mathrm{N}_{\mathrm{m}}$ is the molting times.

Data were first analyzed using one-way analysis of variance ANOVA to detect differences among all treatments. A two-way ANOVA was used to test the effects of lipid and n-3 LC-PUFA levels on growth performance, tissue compositions and fatty acid profiles, and expression of genes related to fatty acid synthesis and lipid metabolism. Data were transformed before analysis as necessary. When there were significant differences $(P<0.05)$, the group means were further compared using Tukey's multiple range tests. All the results are presented as means \pm SEM $(n=3)$. The two-slope broken-line regression analysis was conducted to analyze WG in response to dietary n-3 LC-PUFA level (Figure 1). All statistical analyses were performed using SPSS 23.0 (SPSS, IBM, USA).

\section{Results}

\section{Growth performance}

The growth performance of crabs fed the experimental diets is shown in Table 3. MF was not affected by dietary n-3 LC-PUFA at either lipid level but WG and SGR were significantly influenced by dietary n-3 LC-PUFA at both lipid levels. Crabs fed the diet containing $19.8 \mathrm{mg} \mathrm{g}^{-1} \mathrm{n}-3$ LC-PUFA had higher WG and SGR than those fed the control $\left(0.15 \mathrm{mg} \mathrm{g}^{-1}\right)$ and $24.9 \mathrm{mg} \mathrm{g}^{-1} \mathrm{n}-3$ LC-PUFA diets at $7 \%$ dietary lipid level. Furthermore, crabs fed the diet containing $13.2 \mathrm{mg} \mathrm{g}^{-1} \mathrm{n}-3$ LC-PUFA at $12 \%$ lipid had the highest WG and SGR among all treatments. Two-slope broken-line regression analysis showed that the optimal n-3 LC-PUFA levels were estimated to be $20.1 \mathrm{mg} \mathrm{g}^{-1}$ and $12.7 \mathrm{mg} \mathrm{g}^{-1}$ at $7 \%$ and $12 \%$ dietary lipid level, respectively (Figure. 1). 


\section{Proximate composition in hepatopancreas and muscle}

As shown in Table 4, moisture and lipid contents in muscle were significantly influenced by dietary n-3 LC-PUFA at both lipid levels, with lipid content in muscle significantly decreased with increased dietary n-3 LC-PUFA, although protein content in muscle was not affected by dietary n-3 LC-PUFA at either lipid level. Moisture, lipid and protein contents in hepatopancreas were significantly influenced by dietary n-3 LC-PUFA at both lipid levels, with crabs fed the control diet having the lowest lipid content in hepatopancreas among all treatments. However, protein content in hepatopancreas significantly decreased with increased dietary n-3 LC-PUFA at both lipid levels, with the highest protein content in hepatopancreas found in crabs fed the control diet.

\section{Fatty acids profile of muscle and hepatopancreas}

Principal component analysis (PCA) was used to evaluate the overall effects of dietary n-3 LC-PUFA at two dietary lipid levels on fatty acid compositions of muscle and hepatopancreas (Figure. 2). Fatty acid compositions of crabs fed the control diet were significantly separated from those fed the n-3 LC-PUFA supplemented diets. Full fatty acid compositions of muscle and hepatopancreas are provided in Supplementary Tables 2 and 3.

The fatty acid profiles of muscle fed the experimental diets are presented in Table 5. Monounsaturated fatty acid (MUFA) and n-6 PUFA contents significantly decreased with increased dietary n-3 LC-PUFA at two lipid levels. However, EPA, DHA, n-3 PUFA contents and DHA/EPA ratio significantly increased with increasing dietary n-3 LC-PUFA at both lipid levels. The EPA, DHA and n-3 PUFA contents and DHA/EPA ratio in muscle of initial crabs were higher than those fed the control diet, but lower than those fed the n-3 LC-PUFA-supplemented diets. Muscle of crabs fed all experimental diets had higher total fatty acid (TFA) contents than that of initial crabs. The SFA content in muscle decreased at $7 \%$ dietary lipid but increased at $12 \%$ dietary lipid with dietary n-3 LC-PUFA levels increasing. The n-3/n-6 ratio in muscle increased with increased dietary n-3 LC-PUFA levels.

The fatty acid profiles in hepatopancreas fed the experimental diets are shown in Table 6. Crabs fed the diets supplemented with n-3 LC-PUFA had significantly higher contents of TFA, MUFA, n-3 PUFA, DHA, EPA and DHA/EPA ratio in hepatopancreas than those fed the control diet at both lipid levels, and no significant differences were observed in DHA/EPA ratio of crabs fed the n-3 LC-PUFA supplemented diets. Crabs fed the control diets at both lipid levels had lower EPA, DHA and n-3 
Accepted manuscript

PUFA contents in hepatopancreas than those of initial crab. The EPA, DHA and n-3 PUFA contents were higher than initial crab when crabs fed diets with higher than $7.4 \mathrm{mg} \mathrm{g}^{-1}$ and $13.2 \mathrm{mg} \mathrm{g}^{-1}$ dietary n-3 LC-PUFA at $7 \%$ and $12 \%$ lipid levels, respectively. The DHA/EPA ratio of crabs fed diets supplemented with n-3 LC-PUFA were similar as initial crab and higher than those fed the control diets. The SFA content decreased at $7 \%$ but increased at $12 \%$ dietary lipid with increased n-3 LC-PUFA level. The n-3/n-6 PUFA ratio in hepatopancreas increased with increased dietary n-3 LC-PUFA level, but was lower than that in initial crabs. Crabs fed diets containing $12 \%$ lipid had lower n-6 PUFA, n-3 PUFA, EPA and DHA contents in hepatopancreas than those fed the $7 \%$ lipid diets.

\section{Expression of LC-PUFA biosynthesis in hepatopancreas}

The expression of genes related to LC-PUFA biosynthesis in hepatopancreas are shown in Figure 3. The expression levels of $\Delta 6$ FAD in hepatopancreas were up-regulated with increased dietary n-3 LC-PUFA at both lipid levels, with lowest expression level of $\triangle 6$ FAD in hepatopancreas observed in crabs fed the control diets. However, expression levels of ELOVL4 tended to decrease with increasing dietary n-3 LC-PUFA at both lipid levels. The expression levels of ELOVL4 decreased sharply when dietary n-3 LC-PUFA level was higher than $14.8 \mathrm{mg} \mathrm{g}^{-1}$ at $7 \%$ lipid level, and decreased with increasing dietary n-3 LC-PUFA levels at $12 \%$ lipid.

\section{Expression of lipid metabolism in hepatopancreas}

Figure 4 shows the expression levels of genes involved in lipogenesis in hepatopancreas. The expression levels of SREBP-1 in hepatopancreas significantly increased as dietary n-3 LC-PUFA increased from $0.15 \mathrm{mg} \mathrm{g}^{-1}$ to $14.8 \mathrm{mg} \mathrm{g}^{-1}$ and then decreased with further increased dietary $\mathrm{n}-3$ LC-PUFA at $7 \%$ lipid level, and the highest expression level of SREBP-1 was found in crabs fed diets containing $14.8 \mathrm{mg} \mathrm{g}^{-1} \mathrm{n}-3$ LC-PUFA. The expression levels of G6PD showed similar trends at $7 \%$ and $12 \%$ lipid level. Crabs fed diets containing $6.8 \mathrm{mg} \mathrm{g}^{-1} \mathrm{n}-3$ LC-PUFA showed the highest expression levels of 6PGD, and expression levels decreased with increased dietary n-3 LC-PUFA at $12 \%$ lipid. The expression levels of FAS significantly decreased with increased dietary n-3 LC-PUFA at both $7 \%$ and $12 \%$ lipid levels.

The relative expression levels of genes involved in lipolysis and $\beta$-oxidation are presented in Figure 5. The expression levels of CPTI, CPTII and HSL were down-regulated with increased dietary 
n-3 LC-PUFA at both dietary lipid levels. However, expression levels of ACO were significantly up-regulated with increased dietary n-3 LC-PUFA.

\section{Discussion}

In the present study, WG and SGR showed at first an increase and then a decreasing trend with increased dietary n-3 LC-PUFA level regardless of dietary lipid, and the best growth performance was observed in crabs fed diets containing $19.8 \mathrm{mg} \mathrm{g}^{-1}$ and $13.2 \mathrm{mg} \mathrm{g}^{-1}$ dietary $\mathrm{n}-3$ LC-PUFA at $7 \%$ and $12 \%$ lipid, respectively. The results indicated that excessive dietary n-3 LC-PUFA levels led to detrimental effects on growth performance of $S$. paramamosain, which was in agreement with previous studies in $L$. vannamei $^{(4)}$ and Penaeus monodon ${ }^{(30)}$. A hypothesis put forward to explain this negative effect was the possibility that excessive levels of dietary LC-PUFA, which have higher susceptibility to peroxidation, would result in oxidative stress ${ }^{(31)}$. The highest WG value was $81.24 \%$ in the study, which was lower than $300 \%$ in S. paramamosain ${ }^{(20)}$ (initial weight $11.53 \mathrm{~g}$ ) and $200 \%$ in Eriocheir sinensis ${ }^{(32)}$ (initial weight $0.6 \mathrm{~g}$ ). It was well known that the growth of crustaceans, due to an increase in weight gain at molt, is correlated with the molting frequency ${ }^{(33)}$. However, the intermolt would become longer as the individual grows larger. This may be due to different culture species, bigger initial weight and the purified diets, which were used to reduce the effects of natural LC-PUFA in fishmeal and/or fish oil. Usually, purified diets reduce the palatability of feeds for mud crab. The farming of mud crab depends mainly on conventional simple or compound feeds including trash fish, molluscan meat, and animal viscera $^{(20)}$.

Based on two-slope broken-line regression analysis of WG against dietary n-3 LC-PUFA level, the optimal dietary n-3 LC-PUFA levels (DHA/EPA = 1.1) were $20.1 \mathrm{mg} \mathrm{g}^{-1}$ and $12.7 \mathrm{mg} \mathrm{g}^{-1}$ at $7 \%$ and $12 \%$ dietary lipid, respectively. The result observed in the present study was different to those obtained in P. trituberculatus (initial weight $2.17 \mathrm{~g}$ and $24.00 \mathrm{~g}$, respectively) ${ }^{(10-11)}$ where the optimum n-3 LC-PUFA requirement was $23.5 \mathrm{mg} \mathrm{g}^{-1}$ and $23.3 \mathrm{mg} \mathrm{g}^{-1}$ of diet when the dietary lipid was sufficient and DHA/EPA ratios were 0.9 and 1.1, respectively. Different results were also observed in other crustaceans, including Chinese mitten crab (E. sinensis), tiger shrimp (P. monodon), giant freshwater prawn (Macrobrachium rosenbergii) and L. vannamei ${ }^{(4,34-36)}$, which suggested that the optimum n-3 LC-PUFA requirement varies with species, development stages, dietary lipid level, dietary DHA/EPA ratio and feed formulation. On the other hand, the optimal n-3 LC-PUFA level decreased from $20.1 \mathrm{mg} \mathrm{g}^{-1}$ to $12.7 \mathrm{mg} \mathrm{g}^{-1}$ as dietary lipid level increased from $7 \%$ to $12 \%$ in the 


\section{Accepted manuscript}

present study, which showed that n-3 LC-PUFA requirements of $S$. paramamosain could be affected by dietary lipid level, and decreased when crabs were fed higher dietary lipid. However, the requirement of red sea bream (P. major) for dietary n-3 LC-PUFA increased from $1.2-2.2 \mathrm{mg} \mathrm{g}^{-1}$ to 2.7 - $3.2 \mathrm{mg} \mathrm{g}^{-1}$ of dry weight when dietary lipid level increased from $10 \%$ to $15 \%{ }^{(15)}$. This difference may be due to different culture species and/or feed formulations. In the present study, $7 \%$ dietary lipid was lower than the optimum lipid level $(9.50 \%)$ for $S$. paramamosain $^{(20)}$. A previous study demonstrated that L. vannamei could utilize both SFA and PUFA for energy metabolism ${ }^{(13)}$ and, thus, the higher n-3 LC-PUFA requirement at lower dietary lipid in S. paramamosain may be due in part to dietary n-3 LC-PUFA (e.g. EPA) being utilized to supply energy. However, information regarding the relationship between n-3 LC-PUFA requirement and dietary lipid level in crustaceans is limited and still needs to be confirmed and further studied. Additionally, WG and SGR increased significantly with increased dietary lipid level in the present study, which agreed with a previous study on mud crab investigating optimum dietary protein and lipid levels (Cheng et al., unpublished data). These results also indicated that mud crab may have a relatively high lipid requirement and/or high tolerance to increased dietary lipid level.

In the present study, crabs fed the n-3 LC-PUFA supplemented diets had significantly higher lipid contents in hepatopancreas than those fed the control diets, and no significant differences were observed in crabs fed the n-3 LC-PUFA supplemented diets, which was similar to studies in $P$. trituberculatus $^{(10)}$ and Japanese flounders (Paralichthys olivaceus) ${ }^{(37)}$. The results indicated that the hepatopancreas was an important tissue for lipid deposition and energy storage in mud crab. Moreover, dietary n-3 LC-PUFA improved energy storage but prevented excess lipid deposition in hepatopancreas, which was supported by the data on TFA content and expression of genes related to lipid metabolism in the present study. The opposite trend was observed in muscle lipid content, suggesting a differential effect of dietary n-3 LC-PUFA on lipid distribution in different tissues. It was reported that dietary n-3 LC-PUFA reduced muscle lipid content of black seabream (Acanthopagrus schlegelii) ${ }^{(38)}$. However, dietary DHA and EPA increased the lipid content in P. olivaceus $^{(37)}$. Contradictory results about dietary LC-PUFA and lipid content were also observed in crustaceans ${ }^{(10-11)}$. Therefore, the relationship between tissue lipid content and dietary n-3 LC-PUFA levels requires further study in crustaceans. The hepatopancreas protein content decreased with increasing dietary n-3 LC-PUFA levels at each dietary lipid, which partly agreed with the whole-body protein content in P. trituberculatus $^{(11)}$. It has been reported that SFA and MUFA are better than n-3 LC-PUFA as substrates for energy production, and 


\section{Accepted manuscript}

high dietary levels of n-3 LC-PUFA could lead to insufficient energy supply, and thus hepatopancreas protein was also used to supply energy.

It was demonstrated in fish and crustaceans that the fatty acid compositions of liver/hepatopancreas and/or muscle reflected the fatty acid profile of diets ${ }^{(6,13,26)}$. In the present study, the fatty acid compositions in hepatopancreas and muscle showed similar results when presented as absolute quantitative terms. Briefly, the EPA, DHA and n-3 PUFA contents in hepatopancreas increased with increased dietary n-3 LC-PUFA levels. Crabs fed diets supplemented with n-3 LC-PUFA had similar DHA/EPA ratios in hepatopancreas as initial crab, and higher than those fed control diets. In muscle, the DHA/EPA ratio in crabs fed diets containing n-3 LC-PUFA was higher than that in initial crabs. On the one hand, these results indicated selective retention of DHA over EPA or other fatty acids in S. paramamosain for its greater biological value as EFA, which was reported in other species ${ }^{(14)}$. On the other hand, recent study indicated that L. vannamei had the potential ability to convert linolenic acid to EPA and DHA ${ }^{(39)}$. We speculated that S. paramamosain may be able to synthesize DHA from EPA or shorter chain PUFA, albeit the capacity may be low. Thus, when the content of DHA in hepatopancreas was insufficient, it was necessary to synthesize DHA from EPA to satisfy functional roles. The contents of TFA and n-3 PUFA in hepatopancreas increased with increasing dietary n-3 LC-PUFA level, which was consistent with the lipid content data discussed above. However, the SFA content decreased at $7 \%$ dietary lipid but increased at $12 \%$ dietary lipid with increasing dietary n-3 LC-PUFA levels in both hepatopancreas and muscle. This may reflect S. paramamosain utilising SFA for energy metabolism when dietary energy was low as reported in L. vannamei ${ }^{(4,13)}$, with dietary n-3 LC-PUFA suppressing the utilisation of SFA for energy at the higher dietary lipid level. In the present study, the absolute contents of MUFA and n-6 PUFA decreased in muscle but increased in hepatopancreas with increasing dietary n-3 LC-PUFA at both dietary lipid levels, which may indicate a difference in fatty acid deposition in different tissues ${ }^{(4)}$. The n-3/n-6 PUFA ratio is an important index for evaluating the nutritional value of food. The FAO/WHO recommended that the lowest $n-3 / n-6$ PUFA ratio in human food should be $0.1-0.2^{(40)}$, and values above that are more beneficial. In the present study, the ratios of n-3/n-6 PUFA in hepatopancreas and muscle were much higher than 0.2 , other than in hepatopancreas of crabs fed control diets, which were 0.13 and 0.15 at $7 \%$ and $12 \%$ dietary lipid, respectively. The ratios of n-3/n-6 PUFA increased with increasing dietary n-3 LC-PUFA at both dietary lipid levels in both hepatopancreas and muscle, which indicated that dietary n-3 LC-PUFA supplementation in this experiment improved the nutritional value of mud crab. In 
hepatopancreas, the contents of n-6 PUFA, n-3 PUFA, EPA and DHA were lower in crabs fed the diets containing $12 \%$ lipid than those fed $7 \%$ lipid. This may be due to high dietary lipid improved by palmitic acid reduced the proportion of PUFAs in dietary lipid, which agreed with another study on mud crab investigating the relationship between dietary lipid and optimum DHA/EPA (unpublished data).

FAS, G6PD, 6PGD and HSL are known as important proteins involved in the mechanisms of lipogenesis and lipolysis, the gene expression levels of which could be affected by dietary fatty acid profile $^{(41-42)}$. The function of FAS is to catalyze de novo fatty acid synthesis ${ }^{(43)}$, and previous studies have shown that n-3 LC-PUFA downregulate the expression of genes involved in fatty acid synthesis, particularly FAS ${ }^{(42)}$. 6GPD and G6PD are the key regulatory enzymes involved in NADPH production, essential for fatty acid biosynthesis ${ }^{(43-44)}$, while HSL is known to be involved in lipolysis ${ }^{(45)}$. Additionally, SREBP-1 is a transcription factor regulating fatty acid, lipid and cholesterol biosynthesis pathways $^{(44,46)}$, and a study in mouse indicated that LC-PUFA inhibit lipogenesis by downregulating the mRNA expression of SREBP-1 ${ }^{(47)}$. There are few studies on SREBP-1 in crustaceans. SREBP-1 cDNA from the hepatopancreas of mud crab has been cloned, and it was demonstrated that the quantitative expression of SREBP-1 was highly influenced by dietary fatty acids ${ }^{(48)}$. In the current study, the expression levels of FAS and HSL decreased with increasing dietary n-3 LC-PUFA level regardless of dietary lipid level, which agreed with results reported in black seabream ${ }^{(42)}$. Moreover, the SREBP-1, 6GPD and G6PD expression levels increased and then decreased when dietary n-3 LC-PUFA level increased from $0.15 \mathrm{mg} \mathrm{g}^{-1}$ to $24.9 \mathrm{mg} \mathrm{g}^{-1}$ at $7 \%$ dietary lipid, while the expression levels of SREBP-1 and G6PD were down-regulated by increased dietary n-3 LC-PUFA at $12 \%$ dietary lipid. These results indicated that the hepatopancreas of mud crab may require a certain level of lipid to supply energy and maintain function, and dietary n-3 LC-PUFA promotes lipogenesis when lipid intake is insufficient, while it suppresses lipogenesis to prevent the damage caused by excess lipid deposition in hepatopancreas.

The main pathway of fatty acid catabolism is $\beta$-oxidation in mitochondrial matrix and peroxisome ${ }^{(49)}$. Both CPT and ACO are key enzymes of fatty acid $\beta$-oxidation, CPTI can participate in long chain fatty acid oxidation, catalysing the conversion of fatty acid-CoAs to fatty acid carnitines for entering the mitochondrial matrix, and the fatty acyl group is transferred back to CoA by a second enzyme, CPTII ${ }^{(50-51)}$. ACO is the rate-limiting enzyme for fatty acid $\beta$-oxidation in peroxisomes ${ }^{(49)}$. In the present study, the expression levels of CPTI and CPTII showed a decreasing trend with increased 
dietary n-3 LC-PUFA level at both $7 \%$ and $12 \%$ lipid levels suggesting a reduction of transport of long-chain fatty acids into the mitochondrial matrix, which led to an inhibition of fatty acid $\beta$-oxidation in agreement with the hepatopancreas lipid content data. The ACO expression levels were up-regulated by increasing dietary n-3 LC-PUFA at both $7 \%$ and $12 \%$ lipid levels indicating that fatty acid $\beta$-oxidation in peroxisomes was enhanced, opposite to that in mitochondria. The results highlighted the different roles of fatty acid $\beta$-oxidation in mitochondria and peroxisomes. One of steps in DHA biosynthesis through the "Sprecher pathway" is catalysed by ACO in peroxisomes ${ }^{(52)}$. The up-regulation of ACO expression by dietary n-3 LC-PUFA in the present study agrees with the DHA content in hepatopancreas, which may indicate that mud crab require a high level of DHA to maintain physiological function.

Key enzymes involved in LC-PUFA biosynthesis in mud crab have been cloned, including $\Delta 6$ FAD-like $^{(53)}$ and ELOVL4-like ${ }^{(54)}$. It is well established that ELOVL4 effectively elongate $\mathrm{C}_{22}$ PUFA to $\mathrm{C}_{24}$ PUFA and have the potential to participate in the production of DHA in fish ${ }^{(55-56)}$. The $\triangle 6$ FAD is regarded as the rate-limiting enzyme in the LC-PUFA biosynthetic pathway in mammals because it is the first enzyme involved in the bioconversion of $\mathrm{C}_{18}$ PUFA towards longer and more unsaturated homologues, and is also involved in the synthesis of DHA from $\mathrm{EPA}^{(52,57)}$. It is generally accepted that high levels of dietary LC-PUFA can suppress the expression of elongase and desaturase genes ${ }^{(1)}$, which may be the reason for decreased expression of ELOVL4 in the present study. A previous study in orange-spotted grouper (Epinephelus coioides) reported that ELOVL4 mRNA expression was down-regulated in response to high dietary LC-PUFA ${ }^{(55)}$. It was demonstrated that crabs fed soy oil diets had higher ELOVL4 and $\triangle 6$ FAD expression than those fed fish oil diets ${ }^{(4,53)}$, which was opposite in $L$. vannamei ${ }^{(58)}$. In the current study, the expression of $\Delta 6$ FAD increased with increasing dietary n-3 LC-PUFA level at both dietary lipid levels, which was positively related to the expression of ACO. It was reported that both $\triangle 6$ FAD and ACO participate in DHA biosynthesis from EPA through the "Sprecher pathway"(52). The up-regulation of $\Delta 6$ FAD and ACO expression may therefore also indicate that mud crab need high DHA to maintain basic functions and it is necessary to synthesize DHA from EPA. This is further evidence for the selective retention of DHA over EPA in mud crab as well as suggesting the capacity of synthesizing DHA from EPA in vivo. A study in juvenile golden pompano (Trachinotus ovatus) showed a similar result, with the expression of ELOVL4, ELOVL5 and $\Delta 6$ FAD in both liver and brain increasing with increasing dietary DHA/EPA ratios ${ }^{(59)}$. Additionally, the expression of $\triangle 6$ FAD in crabs fed $12 \%$ dietary lipid was higher than those fed $7 \%$ dietary lipid, 
we speculated that higher dietary lipid contained lower proportion of n-3 LC-PUFA in the study, which may be in accordance with the result of DHA content in hepatopancreas. Additionally, the underlying regulation mechanism of ELOVL4 demonstrated that the transcription of ELOVL4 was positively mediated by LXR $\alpha$ directly or indirectly through the regulation of SREBP-1 transcription ${ }^{(56)}$, and expression of $\triangle 6$ FAD was also positively regulated by SREBP-1 ${ }^{(60-61)}$, which was partly in agreement with the results in the present study. However, to the best of our knowledge, information on fatty acid and LC-PUFA biosynthesis in mud crab is lacking, and studies on the above enzymes have only been at the transcriptional level. The function of these enzymes and the underlying mechanisms by which the expression of these genes is regulated requires to be studied.

\section{Conclusion}

In summary, mud crabs have a high lipid requirement and relatively high tolerance to dietary lipid levels. Based on two-slope broken-line regression analysis, the optimal n-3 LC-PUFA requirements of mud crab weight gain were estimated to be $20.1 \mathrm{mg} \mathrm{g}^{-1}$ and $12.7 \mathrm{mg} \mathrm{g}^{-1}$ at $7 \%$ and $12 \%$ dietary lipid levels, respectively. Purified, high-lipid diets rich in palmitic acid reduced the n-3 LC-PUFA requirement of mud crab. Dietary n-3 LC-PUFA promoted energy storage but prevented excess lipid deposition in hepatopancreas.

\section{Declaration of competing interest}

The authors declare that they have no known competing financial interests or personal relationships that could have appeared to influence the work reported in this paper.

\section{Acknowledgments}

This research was supported by National Key R \& D Program of China (2018YFD0900400), China Agriculture Research System-48 (CARS-48), Nature Science Foundation of Zhejiang Province (LY17C190002), Key Research Program of Zhejiang Province of China (2018C02037), Zhejiang Aquaculture Nutrition \& Feed Technology Service Team (ZJANFTST2017-2). This research was also sponsored by the K. C. Wong Magna Fund in Ningbo University. The authors graciously thank Ningbo 
Institute of Materials Technology and Engineering, Chinese Academy of Sciences (NIMTE, CAS) for use of the Agilent Technologies GC-MS 7890B-5977A, USA.

\section{Authorship}

X.W. formulated the research question, designed the study, carried out the study, analyzed the data and wrote the article. M.J. designed the study, assisted in the correction and developed the questions. X.C. was involved in feeding trial and laboratory assessments. J.L. assisted in feeding trial and data analysis. L.J. assisted in the correction and developed the questions. M.B.B. developed the questions, and revised the manuscript. D.R.T. assisted in developing the research questions and revising the manuscript. Q.Z. formulated the research question, designed the study, and revised the manuscript. All the authors approved the final version of the manuscript.

\section{Supplementary data}

Table 1. Sequences of the primers used in this work

Table 2. Fatty acid composition of hepatopancreas of crabs fed the different experimental diets

Table 3. Fatty acid composition of muscle of crabs fed the different experimental diets

Figure 1. Single cell and culture system of mud crab 


\section{References}

1. Tocher DR (2003) Metabolism and functions of lipids and fatty acids in teleost fish. Rev Fish. Sci 11, 107-184.

2. Copeman L, Parrish C, Brown J et al. (2002) Effects of DHA, EPA and AA on the early growth, survival, lipid composition and pigmentation of yellowtail flounder (Limanda ferruginea): a live food enrichment experiment. Aquaculture 210, 185-204.

3. Suprayudi MA, Takeuchi T, Hamasaki K (2004) Effects of Artemia enriched with eicosapentaenoic and docosahexaenoic acid on survival and occurrence of molting failure in megalop larvae of the mud crab Scylla serrata. Fish Sci 70, 650-658.

4. Yang Q, Zhang W, Tan B et al. (2019) Effects of dietary n-3 HUFA on juvenile white shrimp, Litopenaeus vannamei: Growth, feed utilization, antioxidant enzymes activities and fatty acid compositions. Aquacult Res 50, 882-894.

5. NRC (2011) Nutrient requirements of fish and shrimp. National academies press.

6. Nasopoulou C \& Zabetakis IJL (2012) Benefits of fish oil replacement by plant originated oils in compounded fish feeds. A review, 47, 217-224.

7. Feng L (2011) The effect of dietary HUFA on the ovary development, endocrine hormones and tissue biochemical composition of the swimming crab Portunus trituberculatus. Dissertation, Shanghai Ocean University, Shanghai (in Chinese with English abstract).

8. Wang Q (2012) The effect of DHA/EPA and HUFA on nutrition quality of swimming crab, Portunus trituberculatus. Dissertation, Shanghai Ocean University, Shanghai (in Chinese with English abstract).

9. Yang YP (2013) The effects of dietary supplement of Arachidonic acid on ovary development and nutritional quality of swimming crab, Portunus trituberculatus. Dissertation, Shanghai Ocean University, Shanghai (in Chinese with English abstract).

10. Zhang W (2014) Study on the requirements of n-3 series highly unsaturated fatty acids, vitamin C and vitamin E for the swimming crab, Portunus trituberculatus. Dissertation, Ningbo University, Ningbo (in Chinese with English abstract).

11. Hu S (2015) Studies on n-3 highly unsaturated fatty acid requirement of swimming crab (Portunus trituberculatus). Dissertation, Zhejiang Ocean University, Zhoushan (in Chinese with English abstract). 
Accepted manuscript

12. González-Félix ML, Gatlin Iii DM, Lawrence AL et al. (2003) Nutritional evaluation of fatty acids for the open thelycum shrimp, Litopenaeus vannamei: II. Effect of dietary n-3 and n-6 polyunsaturated and highly unsaturated fatty acids on juvenile shrimp growth, survival, and fatty acid composition. Aquacult Nutr 9, 115-122.

13. Zhang W, Wang F, Tan, B et al. (2019) Effects of dietary n-3 HUFA on different growth stages of the white shrimp, Litopenaeus vannamei: Growth, haematological characteristics, enzyme activities and fatty acid profiles. Aquacult Nutr 255, 1098-1114.

14. Izquierdo M (1996) Essential fatty acid requirements of cultured marine fish larvae. Aquacult Nutr 2, 183-191.

15. Takeuchi T, Toyota M, Watanabe T (1992) Dietary value of Artemia enriched with various types of oils for larval striped knife jaw and red seabream. Nippon Suisan Gakkaishi 58, 283-289.

16. Williams CD \& Robinson EH (1988) Response of red drum to various dietary levels of menhaden oil. Aquaculture 70, 107-120.

17. Brinkmeyer RL \& Holt GJ (1998) Highly unsaturated fatty acids in diets for red drum Sciaenops ocellatus larvae. Aquaculture 161, 253-268.

18. Li Y, Ai C, Liu L (2018) Mud crab, Scylla paramamosain China's leading maricultured crab. Aquaculture in China: Success Stories and Modern Trends. pp, 226-233.

19. China Fishery Statistical Yearbook (2019) Compiled by Fishery Bureau of China Agriculture Department. pp. 22.

20. Zhao J, Wen X, Li S et al. (2015) Effects of dietary lipid levels on growth, feed utilization, body composition and antioxidants of juvenile mud crab Scylla paramamosain (Estampador). Aquaculture 435, 200-206.

21. Zhao J, Wen X, Li S et al. (2016) Effects of different dietary lipid sources on tissue fatty acid composition, serum biochemical parameters and fatty acid synthase of juvenile mud crab Scylla paramamosain (E stampador 1949). Aquacult Res 47, 887-899.

22. Dong L, Zhang Q, Xu, M et al. (2017a) Effects of dietary carbohydrate to lipid ratio on growth performance, body composition and digestive enzyme activities of juvenile Scylla paramamosain. Chin J Anim Nutr 29, 979-986.

23. Dong L, Tong T, Zhang Q et al. (2017b) Effect of dietary protein levels on growth performance, body composition, and digestive enzyme activities in mud crab (Scylla paramamosain) juveniles. $J$ Fish Sci China 43, 252-258. 
24. Sheen SS (2000) Dietary cholesterol requirement of juvenile mud crab Scylla serrata. Aquaculture 189, 277-285.

25. Jin M, Wang MQ, Huo YW et al. (2015) Dietary lysine requirement of juvenile swimming crab, Portunus trituberculatus. Aquaculture 448, 1-7.

26. Unnikrishnan U \& Paulraj R (2010) Dietary protein requirement of giant mud crab Scylla serrata juveniles fed iso-energetic formulated diets having graded protein levels. Aquacult Res 41, 278-294.

27. AOAC (2006) Official Methodsof Analysis. 18th ed. Association of Official Analytical Chemists, Arlington, VA.

28. Gao J, Koshio S, Ishikawa M et al. (2012) Effects of dietary palm oil supplements with oxidized and non-oxidized fish oil on growth performances and fatty acid compositions of juvenile Japanese sea bass, Lateolabrax japonicus. Aquaculture 324, 97-103.

29. Livak KJ \& Schmittgen TD (2001) Analysis of relative gene expression data using real-time quantitative PCR and the $2^{-\Delta \Delta C T}$ method. Methods 25, 402-408.

30. Rees JF, Curé K, Piyatiratitivorakul S et al. (1994) Highly unsaturated fatty acid requirements of Penaeus monodon postlarvae: an experimental approach based on Artemia enrichment. Aquaculture 122, 193-207.

31. Kjær MA, Todorcević M, Torstensen BE et al (2008) Dietary n-3 HUFA affects mitochondrial fatty acid beta-oxidation capacity and susceptibility to oxidative stress in Atlantic salmon. Lipids $\mathbf{4 3}$, 813-827.

32. Zhao YT (2013) Effects of dietary dha levels and dha/epa ratios on growth and lipid composition of juvenile chinese mitten crab Eriocheir sinensis. 2013, Dissertation, Shanghai Ocean University, Shanghai (in Chinese with English abstract).

33. Sheen SS \& Wu SW (1999) The effects of dietary lipid levels on the growth response of juvenile mud crab Scylla serrata. Aquaculture 175, 143-153.

34. D'Abramo LR \& Sheen SS (1993) Polyunsaturated fatty acid nutrition in juvenile freshwater prawn Macrobrachium rosenbergii. Aquaculture 115, 63-86.

35. Glencross B \& Smith D (2001) Optimizing the essential fatty acids, eicosapentaenoic and docosahexaenoic acid, in the diet of the prawn, Penaeus monodon. Aquacult Nutr 7, 101-112.

36. Wu X, Wang Z, Cheng Y et al. (2011) Effects of dietary phospholipids and highly unsaturated fatty acids on the precocity, survival, growth and hepatic lipid composition of juvenile Chinese mitten 
Accepted manuscript

crab, Eriocheir sinensis (H. Milne-Edwards). Aquacult Res 42, 457-468.

37. Xue M, Li A, Zhang X (2004) Nutrient requirements for EPA and DHA by juvenile Paralichthys olivaceus. J Fish China 28, 285-291.

38. Ma J, Shao Q, Xu Z et al. (2009) Effects of dietary n-3 HUFA on growth performance and lipid metabolism in juvenile black sea bream, Sparus macrocephalus. J Fish China 33, 639-649.

39. Chen K, Li EC, Gan L et al. (2014). Growth and lipid metabolism of the pacific white shrimp Litopenaeus vannamei at different salinities. J Shellfish Res 33, 825-832.

40. FAO US. (2017) FAO yearbooks of fisheries statistics, food agriculture organization of the United Nations, Rome.

41. Jin M, Monroig Ó, Lu Y et al. (2017a) Dietary DHA/EPA ratio affected tissue fatty acid profiles, antioxidant capacity, hematological characteristics and expression of lipid-related genes but not growth in juvenile black seabream (Acanthopagrus schlegelii). PloS One 12, e0176216.

42. Jin M, Lu Y, Yuan Y et al. (2017b) Regulation of growth, antioxidant capacity, fatty acid profiles, hematological characteristics and expression of lipid related genes by different dietary n-3 highly unsaturated fatty acids in juvenile black seabream (Acanthopagrus schlegelii). Aquaculture 471, $55-65$.

43. Chen QL, Luo Z, Liu, X et al. (2013) Effects of water-borne chronic copper exposure on hepatic lipid metabolism and metal-element composition in Synechogobius hasta. Arch Environ Contam Toxicol 64 (2), 301-315.

44. Zheng JL, Luo Z, Zhu QL et al. (2013) Molecular cloning and expression pattern of 11 genes involved in lipid metabolism in yellow catfish Pelteobagrus fulvidraco. Gene 531, 53-63.

45. Ma J, Shao Q, Xu Z et al. (2013) Effect ofdietary n-3 highlyunsaturated fattyacids on growth, body composition and fatty acid profiles of juvenile black seabream, Acanthopagrus schlegeli (Bleeker). J World Aquacult Soc 44 (3), 311-325.

46. Minghetti M, Leaver MJ, Tocher DR (2011) Transcriptional control mechanisms of genes of lipid and fatty acid metabolism in the Atlantic salmon (Salmo salar L.) established cell line, SHK-1. Biochim Biophys Acta 1811, 194-202.

47. Kim HJ, Takahashi M, Ezaki O (1999) Fish oil feeding decreases mature sterol regulatory element-binding protein 1 (SREBP-1) by down-regulation of SREBP-1c mRNA in mouse liver a possible mechanism for down-regulation of lipogenic enzyme mRNAs. J Biol Chem 274, 25892-25898. 
Accepted manuscript

48. Hao M, Lin Z, Rong H et al. (2018) Sterol regulatory element binding protein-1: Molecular cloning, tissue distribution and gene expression levels in response to nutritional regulation in mud crab, Scylla paramamosain. Biochem Biophys Res Commun 505, 705-711.

49. Lu KL, Xu WN, Wang LN et al. (2014) Hepatic $\beta$-oxidation and regulation of carnitine palmitoyltransferase (CPT) I in blunt snout bream Megalobrama amblycephala fed a high fat diet. Plos One 9, e93135.

50. Kerner J, Hoppel, CL (2000) Fatty acid import into mitochondria. Biochim Biophys Acta 1486, $1-17$.

51. Li L, Limbu SM, Ma Q et al. (2019) The metabolic regulation of dietary L-carnitine in aquaculture nutrition: present status and future research strategies. Rev Aquaculture 11, 1228-1257.

52. Sprecher H (2000) Metabolism of highly unsaturated n-3 and n-6 fatty acids. Biochim Biophys Acta 1486, 219-231.

53. Lin Z, Hao M, Zhu D et al. (2017) Molecular cloning, mRNA expression and nutritional regulation of a $\Delta 6$ fatty acyl desaturase-like gene of mud crab, Scylla paramamosain. Comp Biochem Physiol B: Biochem Mol Biol 208, 29-37.

54. Lin Z, Hao M, Huang Y et al. (2018) Cloning, tissue distribution and nutritional regulation of a fatty acyl Elovl4-like elongase in mud crab, Scylla paramamosain (Estampador, 1949). Comp Biochem Physiol B: Biochem Mol Biol 217, 70-78.

55. Li S, Monroig Ó, Navarro JC et al. (2017a) Molecular cloning and functional characterization of a putative Elovl4 gene and its expression in response to dietary fatty acid profiles in orange-spotted grouper Epinephelus coioides. Aquacult Res 48, 537-552.

56. Li S, Monroig Ó, Wang T et al (2017b). Functional characterization and differential nutritional regulation of putative Elovl5 and Elovl4 elongases in large yellow croaker (Larimichthys crocea). 
Sci Rep 7, 2303.

57. Monroig Ó, Li Y, Tocher DR (2011) Delta-8 desaturation activity varies among fatty acyl desaturases of teleost fish: high activity in delta-6 desaturases of marine species. Comp Biochem Physiol B: Biochem Mol Biol 159, 206-213.

58. Chen K, Li E, Li T et al. (2017) The expression of the $\Delta 6$ fatty acyl desaturase-like gene from Pacific white shrimp (Litopenaeus vannamei) under different salinities and dietary lipid compositions. J Shellfish Res 36, 501-509.

59. Zhang M, Chen C, You, C et al. (2019) Effects of different dietary ratios of docosahexaenoic to eicosapentaenoic acid (DHA/EPA) on the growth, non-specific immune indices, tissue fatty acid compositions and expression of genes related to LC-PUFA biosynthesis in juvenile golden pompano Trachinotus ovatus. Aquaculture 505, 488-495.

60. Dong X, Tan P, Cai Z et al. (2017c) Regulation of FADS2 transcription by SREBP-1 and PPAR-alpha influences LC-PUFA biosynthesis in fish. Sci Rep. 7, 40024.

61. Chen C, Wang S, Zhang M et al. (2019) miR-24 is involved in vertebrate LC-PUFA biosynthesis as demonstrated in marine teleost Siganus canaliculatus. Biochim Biophys Acta 1864, 619-628. 


\section{Figure legends}
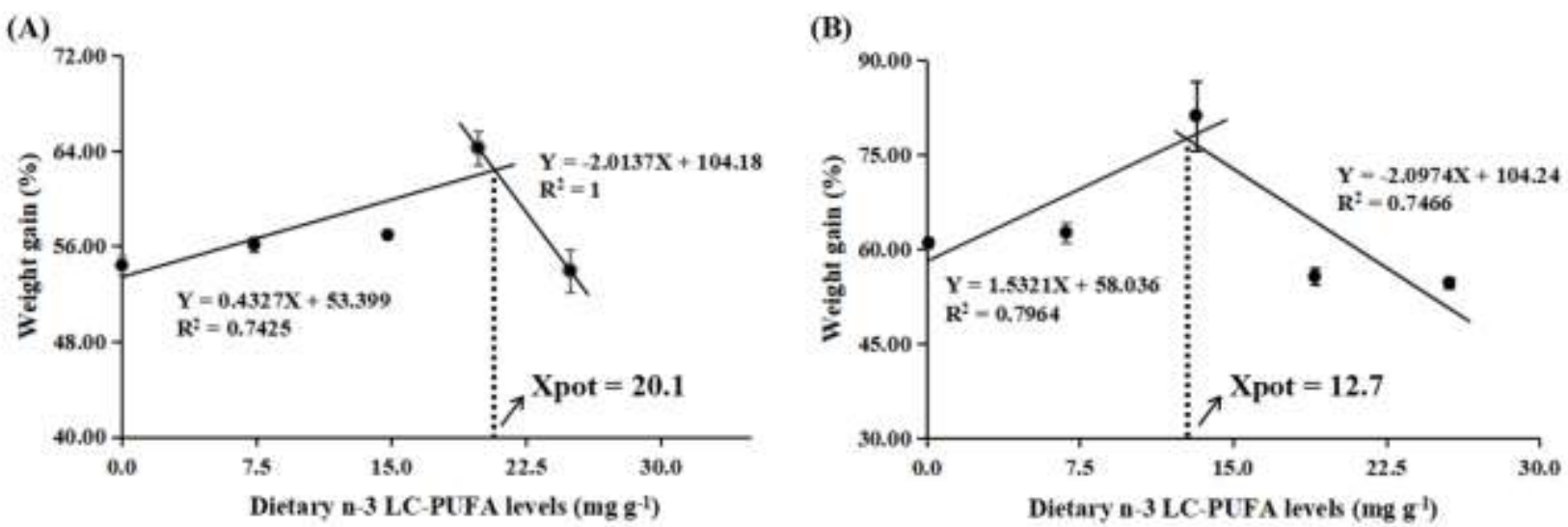

Figure. 1. The relationship between dietary n-3 LC-PUFA levels and weigh gain (WG) of juvenile mud crab fed $7 \%$ (A) and $12 \%$ (B) dietary lipid. The horizontal axis represents the measured dietary n-3 LC-PUFA level (dry matter; mg $\mathrm{g}^{-1}$ ). The Xpot represents the optimal dietary n-3 LC-PUFA level for maximum WG of mud crab. 
(A)

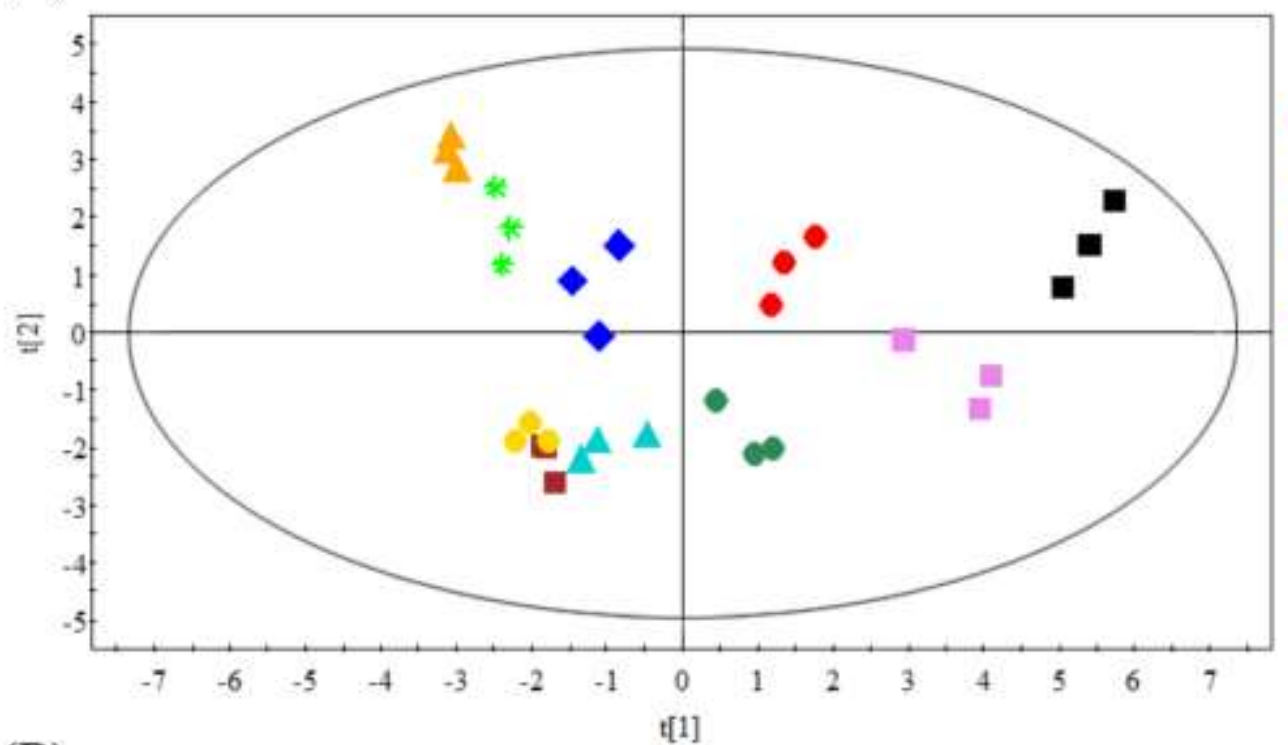

- L7-0.15 $=$ L12-0.1

- L7-7.4 L L12-6.8

$\bullet$ L7-14.8 $A$ L12-13.2

* L7-19.8 = L12-19.0

$\triangle \mathbf{L} 7-24.9=\mathbf{L} 12-25.6$

(B)

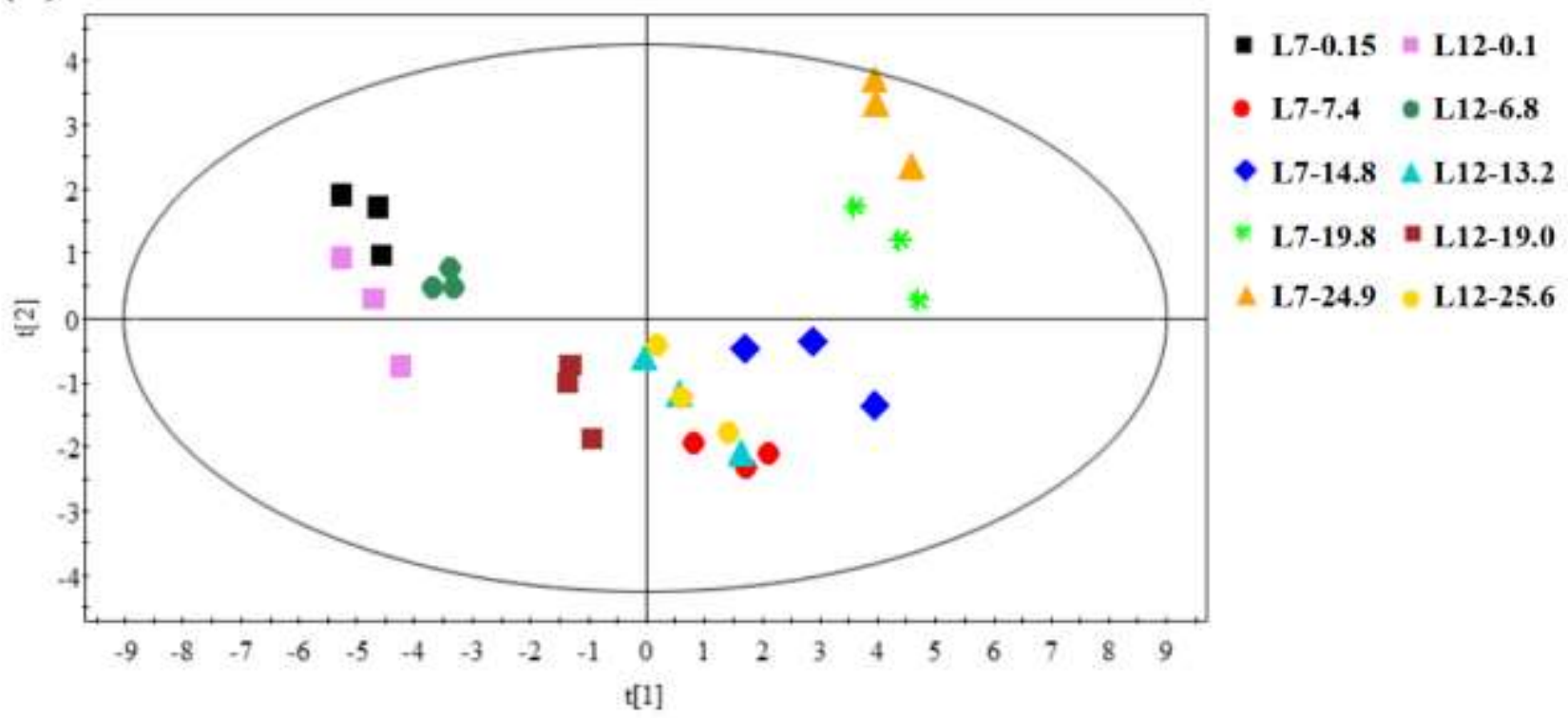

Figure. 2. Principal component analysis (PCA) score plots based on fatty acid profiles of muscle (A) and hepatopancreas (B) of crabs fed different experimental diets. For example, L7-0.15: dietary lipid and n-3 LC-PUFA levels were $7 \%$ and $0.15 \mathrm{mg} \mathrm{g}^{-1}$, respectively. 
Accepted manuscript
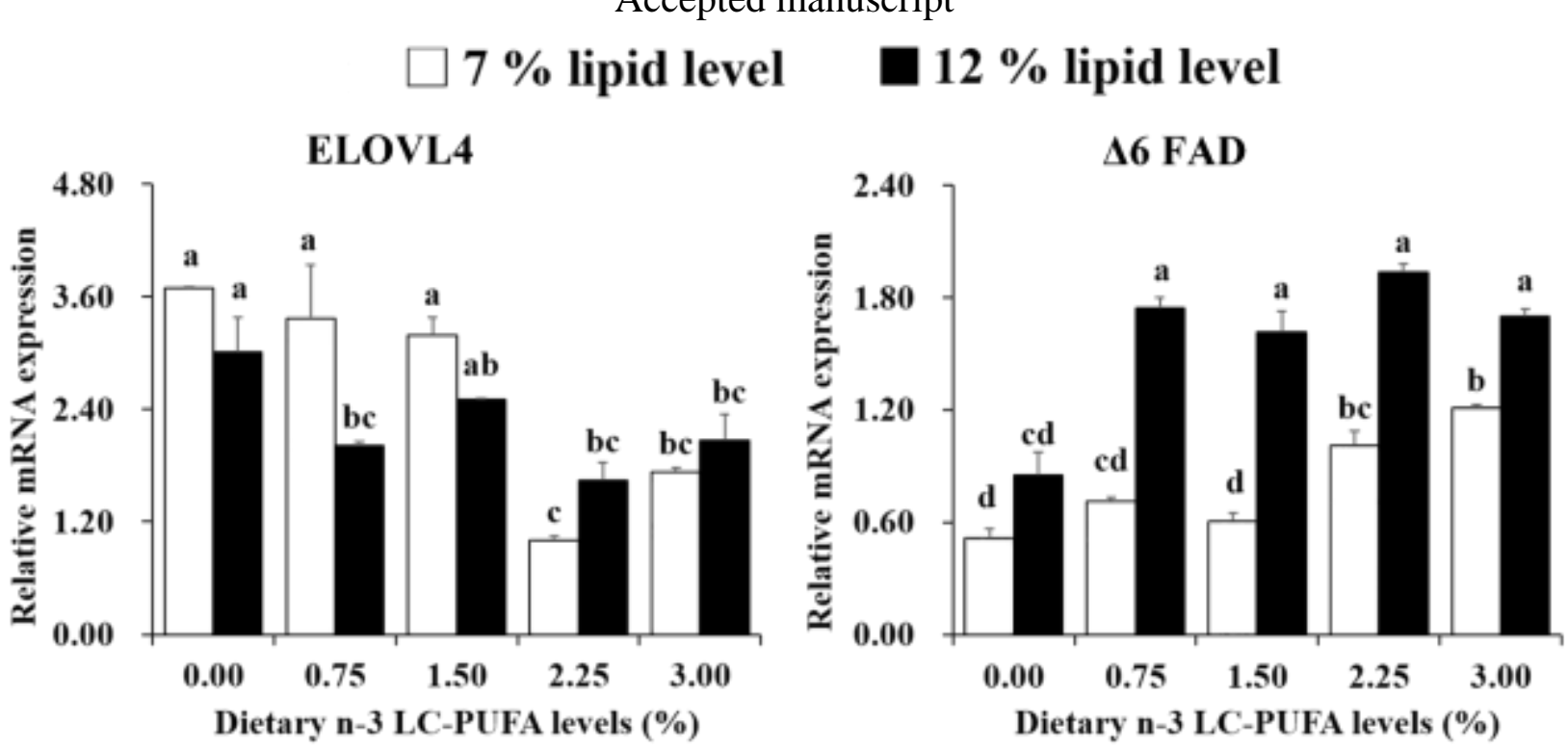

Figure. 3. Effects of different dietary lipid and n-3 LC-PUFA levels on relative mRNA expression levels of genes involved in LC-PUFA biosynthesis in hepatopancreas of S. Paramamosain. $\square, 7 \%$ lipid level; $\square, 12 \%$ lipid level. Values are means \pm S.E.M. $(\mathrm{n}=3)$, and bars bearing different letters are significantly different by Tukey's test $(P<$ 0.05). In order to include data from both dietary lipid levels, the designed n-3 LC-PUFA levels (\%) were used in the X-axis. ELOVL, elongase of very long-chain fatty acids; FAD, fatty acyl desaturase. 
Accepted manuscript
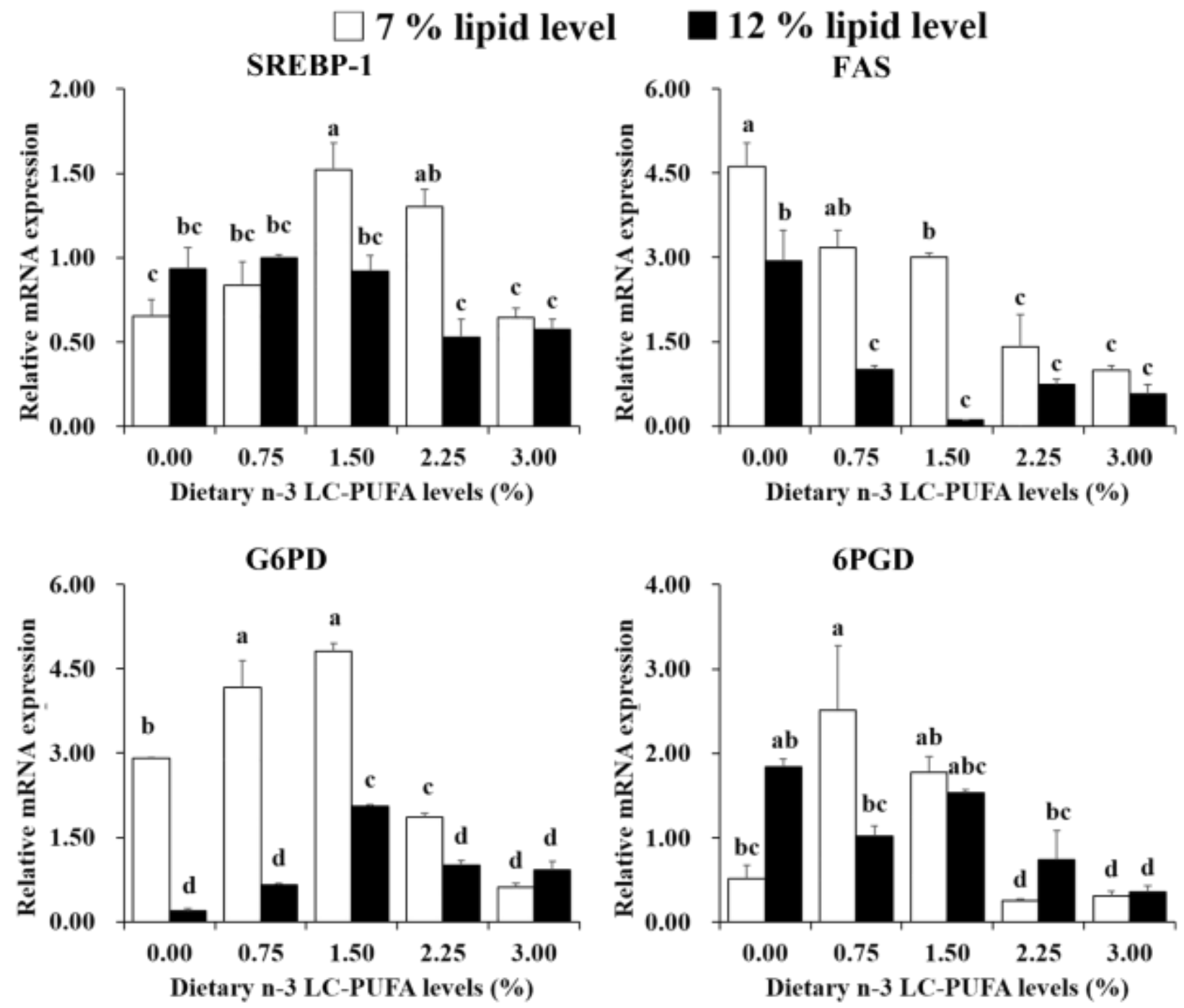

Figure. 4. Effects of different dietary lipid and n-3 LC-PUFA levels on relative mRNA expression of genes involved in lipogenesis in the hepatopancreas of S. Paramamosain. $\square, 7 \%$ lipid level; $\square, 12 \%$ lipid level. Values are means \pm S.E.M. $(\mathrm{n}=3)$, and bars bearing different letters are significantly different by Tukey's test $(P<0.05)$. In order to include the data at both dietary lipid levels, the designed n-3 LC-PUFA levels (\%) were used in the X-axis. SREBP-1: sterol regulator element-binding protein-1; FAS: fatty acid synthase; G6PD: glucose-6-phosphate dehydrogenase; 6PGD: 
Accepted manuscript
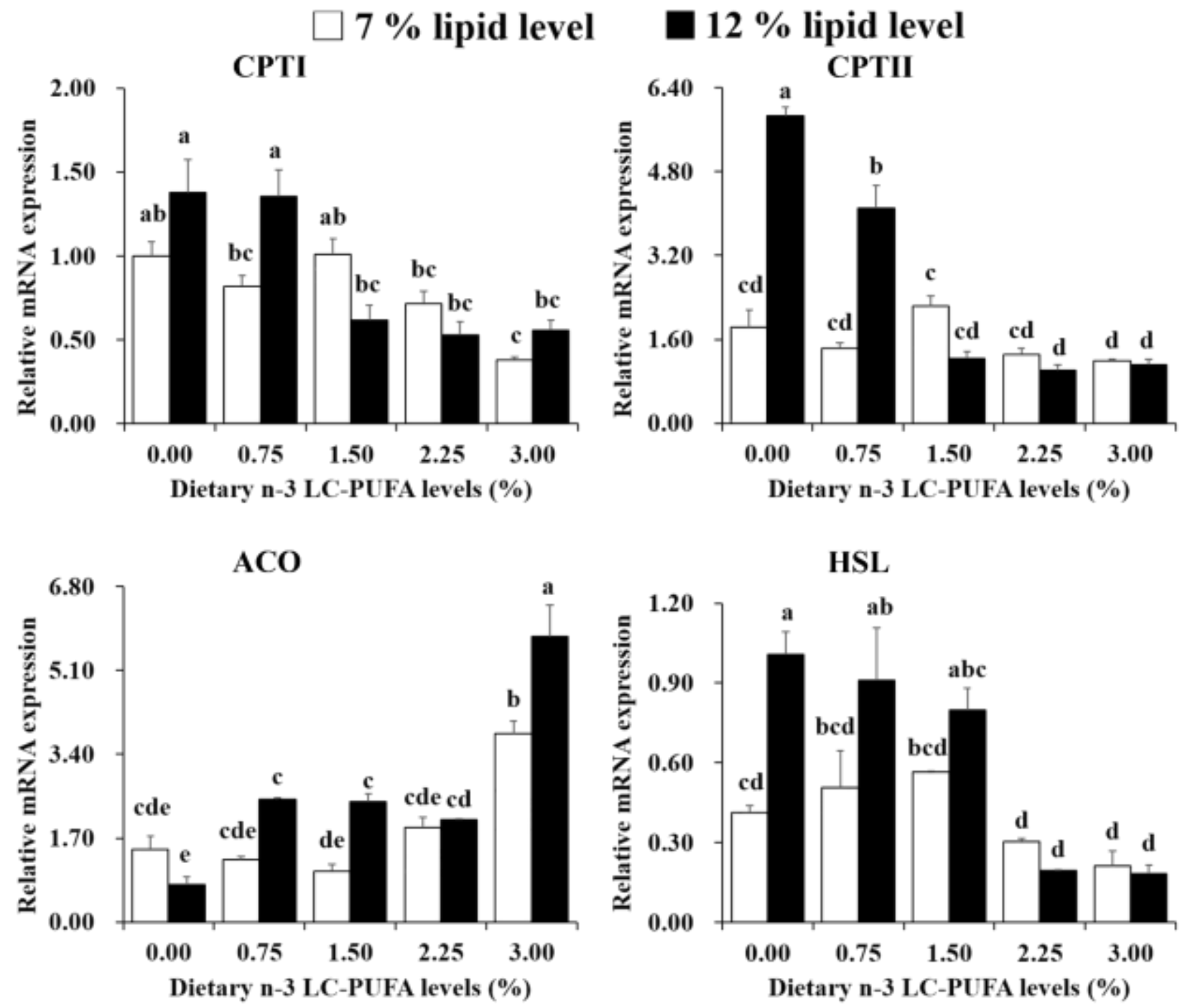

Figure 5. Effects of different dietary lipid and n-3 LC-PUFA levels on relative mRNA expression of genes involved in lipolysis and $\beta$-oxidation in the hepatopancreas of S. Paramamosain. $\square, 7 \%$ lipid level; $\square, 12 \%$ lipid level. Values are means \pm S.E.M. $(\mathrm{n}=3)$, and bars bearing different letters are significantly different by Tukey's test $(P<0.05)$. In order to include the data at both dietary lipid levels, the designed n-3 LC-PUFA levels (\%) were used in the X-axis. CPT: carnitine palmitoyltransferase; HSL: hormone-sensitive triglyceride lipase; ACO, acyl-CoA oxidase. 


\section{Accepted manuscript}

Table 1

Formulation and proximate composition of the experimental diets (dry matter, \%).

\begin{tabular}{|c|c|c|c|c|c|c|c|c|c|c|}
\hline \multirow{3}{*}{ Ingredients } & \multirow{2}{*}{\multicolumn{3}{|c|}{$\frac{7 \% \text { lipid }}{\text { n-3 LC PUFA }\left(\mathrm{mg} \mathrm{g}^{-1}\right)}$}} & & & \multicolumn{5}{|c|}{$12 \%$ lipid } \\
\hline & & & & \multirow[b]{2}{*}{19.8} & \multirow[b]{2}{*}{24.9} & \multirow[b]{2}{*}{0.10} & \multirow[b]{2}{*}{6.8} & \multirow[b]{2}{*}{13.2} & \multirow[b]{2}{*}{19.0} & \multirow[b]{2}{*}{25.6} \\
\hline & 0.15 & 7.4 & 14.8 & & & & & & & \\
\hline Casein $^{*}$ & 27.00 & 27.00 & 27.00 & 27.00 & 27.00 & 27.00 & 27.00 & 27.00 & 27.00 & 27.00 \\
\hline Soy protein concentrate ${ }^{\dagger}$ & 22.56 & 22.56 & 22.56 & 22.56 & 22.56 & 22.56 & 22.56 & 22.56 & 22.56 & 22.56 \\
\hline Wheat flour & 28.00 & 28.00 & 28.00 & 28.00 & 28.00 & 28.00 & 28.00 & 28.00 & 28.00 & 28.00 \\
\hline DHA-enriched oil ${ }^{\star}$ & 0.00 & 0.43 & 0.85 & 1.28 & 1.71 & 0.00 & 0.43 & 0.85 & 1.28 & 1.71 \\
\hline EPA-enriched oil ${ }^{\S}$ & 0.00 & 0.74 & 1.48 & 2.22 & 2.96 & 0.00 & 0.74 & 1.48 & 2.22 & 2.96 \\
\hline ARA-enriched oill & 0.50 & 0.50 & 0.50 & 0.50 & 0.50 & 0.50 & 0.50 & 0.50 & 0.50 & 0.50 \\
\hline Palmitic acid ${ }^{\text {Il }}$ & 4.67 & 3.50 & 2.34 & 1.17 & 0.00 & 9.67 & 8.50 & 7.34 & 6.17 & 5.00 \\
\hline Soybean lecithin & 1.00 & 1.00 & 1.00 & 1.00 & 1.00 & 1.00 & 1.00 & 1.00 & 1.00 & 1.00 \\
\hline Cholesterol & 0.50 & 0.50 & 0.50 & 0.50 & 0.50 & 0.50 & 0.50 & 0.50 & 0.50 & 0.50 \\
\hline Betaine (98\%) & 0.10 & 0.10 & 0.10 & 0.10 & 0.10 & 0.10 & 0.10 & 0.10 & 0.10 & 0.10 \\
\hline Vitamin premix ${ }^{* *}$ & 1.00 & 1.00 & 1.00 & 1.00 & 1.00 & 1.00 & 1.00 & 1.00 & 1.00 & 1.00 \\
\hline Mineral premix ${ }^{* * *}$ & 1.50 & 1.50 & 1.50 & 1.50 & 1.50 & 1.50 & 1.50 & 1.50 & 1.50 & 1.50 \\
\hline $\mathrm{Ca}\left(\mathrm{H}_{2} \mathrm{PO}_{4}\right)_{2}$ & 2.00 & 2.00 & 2.00 & 2.00 & 2.00 & 2.00 & 2.00 & 2.00 & 2.00 & 2.00 \\
\hline Choline chloride & 0.20 & 0.20 & 0.20 & 0.20 & 0.20 & 0.20 & 0.20 & 0.20 & 0.20 & 0.20 \\
\hline Cellulose & 8.97 & 8.97 & 8.97 & 8.97 & 8.97 & 3.97 & 3.97 & 3.97 & 3.97 & 3.97 \\
\hline Sodium alginate & 2.00 & 2.00 & 2.00 & 2.00 & 2.00 & 2.00 & 2.00 & 2.00 & 2.00 & 2.00 \\
\hline Total & 100.00 & 100.00 & 100.00 & 100.00 & 100.00 & 100.00 & 100.00 & 100.00 & 100.00 & 100.00 \\
\hline \multicolumn{11}{|l|}{ Proximate composition } \\
\hline Moisture & 11.56 & 11.13 & 12.05 & 10.35 & 11.29 & 11.05 & 10.03 & 10.64 & 10.76 & 10.46 \\
\hline Crude protein & 45.57 & 45.49 & 44.82 & 45.21 & 44.38 & 44.77 & 45.61 & 45.89 & 45.35 & 45.06 \\
\hline Crude lipid & 6.51 & 6.52 & 6.89 & 6.52 & 6.48 & 11.93 & 11.73 & 11.85 & 11.69 & 11.90 \\
\hline Ash & 5.53 & 5.98 & 5.87 & 5.02 & 6.21 & 5.61 & 5.96 & 6.17 & 6.35 & 5.77 \\
\hline
\end{tabular}

"Casein, $89.55 \%$ crude protein and $0.2 \%$ crude lipid.

${ }^{\dagger}$ Soy protein concentrate, $69.88 \%$ crude protein and $0.51 \%$ crude lipid.

${ }^{*}$ DHA-enriched oil, DHA content, $406.5 \mathrm{mg} \mathrm{g}^{-1}$ oil.

${ }^{\S}$ EPA-enriched oil, EPA content, $462.5 \mathrm{mg} \mathrm{g}^{-1}$ oil; DHA content, $235.6 \mathrm{mg} \mathrm{g}^{-1}$ oil.

" ARA-enriched oil, ARA content, $468.0 \mathrm{mg} \mathrm{g}^{-1}$ oil.

${ }^{\mathbb{I}}$ Palmitic acid, Palmitic acid content, 97\% of total fatty acids, in the form of methylester; Shanghai Yiji Chemical Co., Ltd., China.

*** Vitamin premix and Mineral premix were based on Jin et al. $(2015)^{(25)}$. 
Table 2

Fatty acid compositions of the experimental diets $\left(\mathrm{mg} \mathrm{g}^{-1}\right.$, dry matter).

\begin{tabular}{|c|c|c|c|c|c|c|c|c|c|c|}
\hline \multirow{3}{*}{ FA } & \multicolumn{5}{|c|}{$7 \%$ lipid } & \multicolumn{5}{|c|}{$12 \%$ lipid } \\
\hline & \multicolumn{10}{|c|}{ n-3 LC PUFA (mg g g $\left.^{-1}\right)$} \\
\hline & 0.15 & 7.4 & 14.8 & 19.8 & 24.9 & 0.10 & 6.8 & 13.2 & 19.0 & 25.6 \\
\hline 14:0 & 0.37 & 0.32 & 0.28 & 0.21 & 0.22 & 0.62 & 0.54 & 0.58 & 0.50 & 0.45 \\
\hline 16:0 & 29.81 & 25.38 & 19.99 & 12.77 & 6.23 & 62.53 & 56.09 & 49.71 & 43.28 & 36.84 \\
\hline 18:0 & 1.78 & 1.89 & 2.23 & 2.19 & 2.24 & 1.79 & 1.36 & 2.20 & 2.29 & 2.32 \\
\hline 20:0 & 0.14 & 0.17 & 0.23 & 0.23 & 0.27 & 0.14 & 0.08 & 0.20 & 0.39 & 0.25 \\
\hline$\sum \mathrm{SFA}^{*}$ & 32.10 & 27.76 & 22.73 & 15.40 & 8.97 & 65.08 & 58.08 & 52.69 & 46.46 & 39.87 \\
\hline $16: 1 n-7$ & 0.07 & 0.09 & 0.16 & 0.19 & 0.19 & 0.09 & 0.05 & 0.12 & 0.14 & 0.18 \\
\hline 18:1n-9 & 5.40 & 5.95 & 7.07 & 7.27 & 7.47 & 5.42 & 5.28 & 6.69 & 7.04 & 7.51 \\
\hline 20:1n-9 & 0.11 & 0.16 & 0.24 & 0.27 & 0.27 & 0.11 & 0.12 & 0.25 & 0.26 & 0.35 \\
\hline $22: 1 n-11$ & 0.08 & 0.12 & 0.00 & 0.00 & 0.22 & 0.00 & 0.00 & 0.00 & 0.00 & 0.00 \\
\hline$\sum$ MUFA $^{\dagger}$ & 5.58 & 6.20 & 7.46 & 7.74 & 7.93 & 7.62 & 7.45 & 8.06 & 7.45 & 8.04 \\
\hline $18: 2 n-6$ & 10.47 & 10.95 & 13.24 & 12.72 & 11.15 & 11.76 & 11.50 & 12.43 & 12.22 & 12.17 \\
\hline $18: 3 n-6$ & 0.25 & 0.29 & 0.34 & 0.37 & 0.34 & 0.29 & 0.04 & 0.30 & 0.00 & 0.39 \\
\hline $20: 2 n-6$ & 0.06 & 0.07 & 0.11 & 0.11 & 0.09 & 0.05 & 0.35 & 0.11 & 0.10 & 0.11 \\
\hline $20: 4 n-6$ & 2.08 & 2.13 & 2.93 & 2.81 & 2.60 & 2.33 & 2.78 & 2.09 & 2.73 & 2.87 \\
\hline $22: 4 n-6$ & 0.05 & 0.04 & 0.05 & 0.08 & 0.08 & 0.04 & 0.11 & 0.00 & 0.00 & 0.05 \\
\hline$\sum \mathrm{n}-6$ PUFA & 14.98 & 15.60 & 19.60 & 18.89 & 16.87 & 16.79 & 17.56 & 18.01 & 17.77 & 18.47 \\
\hline $18: 3 n-3$ & 0.95 & 1.04 & 1.32 & 1.29 & 1.20 & 1.05 & 1.11 & 1.23 & 1.12 & 1.29 \\
\hline $18: 4 n-3$ & 0.01 & 0.13 & 0.35 & 0.45 & 0.52 & 0.00 & 0.15 & 0.30 & 0.98 & 0.56 \\
\hline $20: 4 n-3$ & 0.00 & 0.08 & 0.25 & 0.32 & 0.36 & 0.00 & 0.08 & 0.19 & 0.28 & 0.34 \\
\hline $\mathrm{EPA}^{\S}$ & 0.15 & 3.53 & 6.62 & 8.93 & 11.55 & 0.00 & 3.08 & 6.08 & 8.52 & 11.56 \\
\hline $22: 5 n-3$ & 0.00 & 0.12 & 0.30 & 0.32 & 0.45 & 0.00 & 0.31 & 0.29 & 0.33 & 0.35 \\
\hline DHA ${ }^{\|}$ & 0.00 & 3.64 & 7.64 & 10.25 & 12.59 & 0.10 & 3.37 & 6.63 & 9.86 & 13.33 \\
\hline$\sum \mathrm{n}-3 \mathrm{PUFA}^{\mathrm{II}}$ & 1.10 & 8.54 & 16.47 & 21.57 & 26.65 & 1.15 & 8.09 & 14.71 & 21.10 & 27.43 \\
\hline n-3/n-6 PUFA & 0.07 & 0.55 & 0.84 & 1.14 & 1.58 & 0.07 & 0.46 & 0.82 & 1.19 & 1.49 \\
\hline DHA/EPA & 0.00 & 1.03 & 1.15 & 1.15 & 1.09 & / & 1.09 & 1.09 & 1.16 & 1.15 \\
\hline$\sum \mathrm{n}-3$ LC-PUFA ${ }^{* *}$ & 0.15 & 7.37 & 14.80 & 19.82 & 24.94 & 0.10 & 6.83 & 13.18 & 18.99 & 25.57 \\
\hline
\end{tabular}

${ }^{*}$ SFA, saturated fatty acids: 14:0, 16:0, 18:0, 20:0. ${ }^{\dagger}$ MUFA, monounsaturated fatty acids: 16:1n-7, 18:1n-9, C0:1n-9. n-6 PUFA, n-6 polyunsaturated fatty acids: 18:2n-6, 18:3n-6, 20:2n-6, 20:4n-6, 22:4n-6. ${ }^{\S}$ EPA, 20:5n-3. " DHA, 22:6n-3. "I n-3 PUFA, n-3 polyunsaturated fatty acids: 18:3n-3, 18:4n-3, 20:4n-3, EPA, 22:5n-3, DHA. ** n-3 LC-PUFA, n-3 long chain polyunsaturated fatty acids: 20:4n-3, EPA, 22:5n-3, DHA. 


\section{Accepted manuscript}

Table 3

Growth performance and molting frequency of mud crab fed the experimental diets for 8 weeks.

\begin{tabular}{|c|c|c|c|c|c|c|c|c|c|}
\hline \multirow{2}{*}{ Lipid } & \multirow{2}{*}{ n-3 LC-PUFA (mg g ${ }^{-1}$ ) } & \multicolumn{2}{|c|}{ Initial weight (g) } & \multicolumn{2}{|c|}{$\mathrm{WG}^{*}(\%)$} & \multicolumn{2}{|c|}{$\operatorname{SGR}^{\dagger}\left(\% \mathrm{~d}^{-1}\right)$} & \multicolumn{2}{|l|}{$\mathrm{MF}^{*}$} \\
\hline & & Mean & SEM & Mean & SEM & Mean & SEM & Mean & SEM \\
\hline \multirow{5}{*}{$7 \%$} & 0.15 & 31.17 & 1.03 & $54.41^{\mathrm{c}}$ & 0.79 & $0.68^{\mathrm{c}}$ & 0.01 & 0.99 & 0.99 \\
\hline & 7.4 & 29.61 & 0.23 & $56.14^{\mathrm{bc}}$ & 0.62 & $0.70^{\mathrm{bc}}$ & 0.01 & 0.87 & 0.87 \\
\hline & 14.8 & 30.94 & 0.93 & $56.95^{\mathrm{bc}}$ & 0.19 & $0.70^{\mathrm{bc}}$ & 0.00 & 0.79 & 0.79 \\
\hline & 19.8 & 29.28 & 0.54 & $64.27^{\mathrm{b}}$ & 1.40 & $0.78^{\mathrm{b}}$ & 0.01 & 0.92 & 0.92 \\
\hline & 24.9 & 29.92 & 1.33 & $53.96^{\mathrm{c}}$ & 1.81 & $0.67^{\mathrm{c}}$ & 0.02 & 0.81 & 0.81 \\
\hline \multirow{5}{*}{$12 \%$} & 0.1 & 30.81 & 0.29 & $61.03^{\mathrm{bc}}$ & 0.74 & $0.75^{\mathrm{bc}}$ & 0.01 & 0.83 & 0.83 \\
\hline & 6.8 & 31.55 & 1.12 & $62.65^{\mathrm{bc}}$ & 1.55 & $0.76^{\mathrm{b}}$ & 0.02 & 0.81 & 0.81 \\
\hline & 13.2 & 30.21 & 0.96 & $81.24^{\mathrm{a}}$ & 5.49 & $0.93^{\mathrm{a}}$ & 0.05 & 0.97 & 0.97 \\
\hline & 19.0 & 32.04 & 0.62 & $55.67^{\mathrm{bc}}$ & 1.27 & $0.69^{\mathrm{bc}}$ & 0.01 & 0.87 & 0.87 \\
\hline & 25.6 & 29.97 & 0.46 & $54.71^{\mathrm{bc}}$ & 0.81 & $0.68^{\mathrm{c}}$ & 0.01 & 0.88 & 0.88 \\
\hline \multicolumn{10}{|c|}{ ANOVA (p-value) } \\
\hline \multicolumn{2}{|c|}{ Lipid } & & & 0.000 & & 0.000 & & 0.827 & \\
\hline \multicolumn{2}{|c|}{ n-3 LC-PUFA } & & & 0.000 & & 0.000 & & 0.944 & \\
\hline \multicolumn{2}{|c|}{ Interaction } & & & 0.000 & & 0.000 & & 0.312 & \\
\hline
\end{tabular}

Data were represented as means \pm S.E.M. A two-way analysis of variance was performed to evaluate the $2 \times 5$ factorial design with three replicates of each treatment. Tukey's multiple-range test was applied when significant differences $(P$ $<0.05$ ) were detected among dietary treatments. Values in the same column with different superscripts are significantly different $(P<0.05)$. The below is same.

${ }^{*}$ WG: weight gain. ${ }^{\dagger}$ SGR: specific growth rate. ${ }^{\star}$ MF: molting frequency. 
Accepted manuscript

Table 4

Proximate composition in muscle and hepatopancreas of mud crab fed the experimental diets (dry matter) for 8 weeks.

\begin{tabular}{|c|c|c|c|c|c|c|c|c|c|c|c|c|c|}
\hline \multirow{3}{*}{ Lipid } & \multirow{3}{*}{ n-3 LC-PUFA ( $\left.\mathrm{mg} \mathrm{g}^{-1}\right)$} & \multicolumn{6}{|c|}{ Muscle } & \multicolumn{6}{|c|}{ Hepatopancreas } \\
\hline & & \multicolumn{2}{|c|}{ Moisture (\%) } & \multicolumn{2}{|c|}{ Lipid $(\%)$} & \multicolumn{2}{|c|}{ Protein $(\%)$} & \multicolumn{2}{|c|}{ Moisture (\%) } & \multicolumn{2}{|c|}{ Lipid (\%) } & \multicolumn{2}{|c|}{ Protein $(\%)$} \\
\hline & & Mean & SEM & Mean & SEM & Mean & SEM & Mean & SEM & Mean & SEM & Mean & SEM \\
\hline \multirow{5}{*}{$7 \%$} & 0.15 & $80.57^{\mathrm{bc}}$ & 0.17 & $7.98^{\mathrm{ab}}$ & 0.36 & 83.69 & 0.22 & $73.08^{\mathrm{ab}}$ & 0.50 & $25.88^{\mathrm{c}}$ & 0.86 & $45.63^{\mathrm{ab}}$ & 1.80 \\
\hline & 7.4 & $80.27^{\mathrm{c}}$ & 0.05 & $5.74^{\mathrm{c}}$ & 0.63 & 81.44 & 0.92 & $72.00^{\mathrm{b}}$ & 0.32 & $38.83^{\mathrm{ab}}$ & 1.57 & $38.84^{\mathrm{b}}$ & 0.26 \\
\hline & 14.8 & $80.23^{\mathrm{c}}$ & 0.24 & $5.31^{\mathrm{c}}$ & 0.47 & 82.47 & 1.15 & $71.93^{\mathrm{b}}$ & 1.09 & $39.92^{\mathrm{a}}$ & 2.18 & $39.73^{\mathrm{bc}}$ & 0.86 \\
\hline & 19.8 & $80.16^{\mathrm{c}}$ & 0.30 & $5.12^{c}$ & 0.19 & 83.70 & 0.62 & $70.62^{b}$ & 0.73 & $44.12^{\mathrm{a}}$ & 1.97 & $37.41^{b}$ & 0.80 \\
\hline & 24.9 & $81.48^{\mathrm{ab}}$ & 0.35 & $5.74^{\mathrm{c}}$ & 0.61 & 84.24 & 0.98 & $70.81^{b}$ & 0.83 & $41.40^{\mathrm{a}}$ & 0.46 & $36.04^{\mathrm{b}}$ & 0.98 \\
\hline \multirow{5}{*}{$12 \%$} & 0.1 & $81.35^{\mathrm{ab}}$ & 0.20 & $8.29^{\mathrm{a}}$ & 0.11 & 85.08 & 0.04 & $78.73^{\mathrm{a}}$ & 0.88 & $32.08^{\mathrm{bc}}$ & 2.13 & $48.53^{\mathrm{a}}$ & 0.77 \\
\hline & 6.8 & $81.10^{\mathrm{abc}}$ & 0.07 & $5.55^{\mathrm{c}}$ & 0.45 & 82.38 & 2.14 & $77.87^{\mathrm{a}}$ & 0.58 & $44.47^{\mathrm{a}}$ & 1.49 & $48.21^{\mathrm{a}}$ & 0.65 \\
\hline & 13.2 & $80.60^{\mathrm{bc}}$ & 0.10 & $5.78^{\mathrm{c}}$ & 0.20 & 83.49 & 0.40 & $72.48^{\mathrm{b}}$ & 1.36 & $43.05^{\mathrm{a}}$ & 0.45 & $38.75^{\mathrm{b}}$ & 1.75 \\
\hline & 19.0 & $81.75^{\mathrm{a}}$ & 0.10 & $5.28^{\mathrm{c}}$ & 0.27 & 85.11 & 0.50 & $73.83^{\mathrm{ab}}$ & 0.84 & $43.18^{\mathrm{a}}$ & 1.41 & $38.39^{\mathrm{b}}$ & 1.33 \\
\hline & 25.6 & $81.32^{\mathrm{ab}}$ & 0.01 & $6.03^{\mathrm{bc}}$ & 0.36 & 83.46 & 0.90 & $72.55^{\mathrm{ab}}$ & 2.12 & $42.87^{\mathrm{a}}$ & 1.84 & $36.43^{\mathrm{b}}$ & 1.91 \\
\hline \multicolumn{14}{|c|}{ ANOVA (p-value) } \\
\hline \multicolumn{2}{|l|}{ Lipid } & \multicolumn{2}{|c|}{0.000} & \multicolumn{2}{|c|}{0.410} & \multicolumn{2}{|c|}{0.209} & \multicolumn{2}{|c|}{0.000} & \multicolumn{2}{|c|}{0.005} & \multicolumn{2}{|c|}{0.004} \\
\hline \multicolumn{2}{|c|}{ n-3 LC-PUFA } & \multicolumn{2}{|c|}{0.001} & \multicolumn{2}{|c|}{0.000} & \multicolumn{2}{|c|}{0.082} & \multicolumn{2}{|c|}{0.001} & \multicolumn{2}{|c|}{0.000} & \multicolumn{2}{|c|}{0.000} \\
\hline \multicolumn{2}{|c|}{ Interaction } & \multicolumn{2}{|c|}{0.003} & \multicolumn{2}{|c|}{0.939} & \multicolumn{2}{|c|}{0.778} & \multicolumn{2}{|c|}{0.073} & \multicolumn{2}{|c|}{0.171} & \multicolumn{2}{|c|}{0.004} \\
\hline
\end{tabular}


Table 5

Fatty acid profiles in muscle of mud crab fed the experimental diets ( $\mathrm{mg} \mathrm{g}^{-1}$, dry matter) for 8 weeks.

\begin{tabular}{|c|c|c|c|c|c|c|c|c|c|c|c|c|c|c|c|c|c|c|c|}
\hline \multirow{2}{*}{ Lipid } & \multirow{2}{*}{ n-3 LC-PUFA (mg g $\left.{ }^{-1}\right)$} & \multicolumn{2}{|c|}{$\sum \mathrm{SFA}^{*}$} & \multicolumn{2}{|c|}{$\sum$ MUFA $^{\dagger}$} & \multicolumn{2}{|c|}{$\sum \mathrm{n}-6 \mathrm{PUFA}^{\ddagger}$} & \multicolumn{2}{|c|}{$\sum \mathrm{n}-3$ PUFA $^{\S}$} & \multicolumn{2}{|c|}{ EPA" } & \multicolumn{2}{|c|}{$\mathrm{DHA}^{\mathrm{qI}}$} & \multicolumn{2}{|c|}{ DHA/EPA } & \multicolumn{2}{|c|}{$n-3 / n-6$} & \multicolumn{2}{|c|}{$\sum \mathrm{TFA}^{* * *}$} \\
\hline & & Mean & SEM & Mean & SEM & Mean & SEM & Mean & SEM & Mean & SEM & Mean & SEM & Mean & SEM & Mean & SEM & Mean & SEM \\
\hline \multirow[t]{3}{*}{ Initial } & & 4.94 & & 3.41 & & 2.65 & & 7.23 & & 4.20 & & 2.67 & & 0.64 & & 2.74 & & 18.27 & \\
\hline & 0.15 & $8.43^{\mathrm{a}}$ & 0.21 & $4.61^{\mathrm{a}}$ & 0.17 & $8.07^{\mathrm{a}}$ & 0.12 & $6.52^{\mathrm{e}}$ & 0.10 & $3.80^{\mathrm{d}}$ & 0.05 & $2.21^{\mathrm{e}}$ & 0.04 & $0.58^{\mathrm{d}}$ & 0.00 & $0.81^{\mathrm{g}}$ & 0.00 & 27.62 & 0.60 \\
\hline & 7.4 & $8.27^{\mathrm{a}}$ & 0.16 & $3.87^{\mathrm{bc}}$ & 0.08 & $6.73^{\mathrm{b}}$ & 0.20 & $8.64^{\mathrm{d}}$ & 0.25 & $4.96^{\mathrm{c}}$ & 0.15 & $3.28^{\mathrm{d}}$ & 0.13 & $0.66^{\mathrm{cd}}$ & 0.02 & $1.28^{\mathrm{f}}$ & 0.00 & 27.52 & 0.69 \\
\hline \multirow[t]{5}{*}{$7 \%$} & 14.8 & $8.16^{\mathrm{ab}}$ & 0.32 & $3.43^{\mathrm{c}}$ & 0.02 & $5.85^{\mathrm{c}}$ & 0.24 & $10.09^{\mathrm{bc}}$ & 0.18 & $5.26^{\mathrm{bc}}$ & 0.16 & $4.52^{\mathrm{bc}}$ & 0.04 & $0.86^{\mathrm{ab}}$ & 0.02 & $1.73^{\mathrm{d}}$ & 0.04 & 27.53 & 0.73 \\
\hline & 19.8 & $7.97^{\mathrm{ab}}$ & 0.12 & $3.46^{\mathrm{cd}}$ & 0.05 & $5.62^{\mathrm{cd}}$ & 0.14 & $11.32^{\mathrm{a}}$ & 0.19 & $5.77^{\mathrm{ab}}$ & 0.09 & $5.20^{\mathrm{a}}$ & 0.10 & $0.90^{\mathrm{a}}$ & 0.01 & $2.02^{\mathrm{bc}}$ & 0.02 & 28.37 & 0.49 \\
\hline & 24.9 & $7.31^{\mathrm{b}}$ & 0.14 & $3.40^{\mathrm{c}}$ & 0.05 & $5.34^{\mathrm{cd}}$ & 0.10 & $10.73^{\mathrm{ab}}$ & 0.22 & $5.38^{\mathrm{abc}}$ & 0.19 & $5.04^{\mathrm{ab}}$ & 0.06 & $0.94^{\mathrm{a}}$ & 0.03 & $2.01^{\mathrm{bc}}$ & 0.02 & 26.78 & 0.46 \\
\hline & 0.1 & $7.93^{\mathrm{ab}}$ & 0.11 & $4.04^{b}$ & 0.05 & $7.24^{\mathrm{ab}}$ & 0.29 & $6.33^{\mathrm{e}}$ & 0.17 & $3.83^{\mathrm{d}}$ & 0.04 & $2.07^{\mathrm{e}}$ & 0.12 & $0.54^{\mathrm{d}}$ & 0.03 & $0.88^{\mathrm{g}}$ & 0.04 & 25.53 & 0.51 \\
\hline & 6.8 & $8.16^{\mathrm{ab}}$ & 0.02 & $4.08^{\mathrm{b}}$ & 0.03 & $4.79^{\mathrm{d}}$ & 0.02 & $9.59^{\mathrm{cd}}$ & 0.08 & $5.25^{\mathrm{bc}}$ & 0.05 & $3.92^{\mathrm{c}}$ & 0.04 & $0.75^{\mathrm{bc}}$ & 0.01 & $1.55^{\mathrm{e}}$ & 0.02 & 26.62 & 0.08 \\
\hline \multirow[t]{3}{*}{$12 \%$} & 13.2 & $8.06^{\mathrm{ab}}$ & 0.30 & $3.33^{\mathrm{c}}$ & 0.12 & $5.16^{\mathrm{cd}}$ & 0.19 & $10.13^{\mathrm{bc}}$ & 0.28 & $5.32^{\mathrm{bc}}$ & 0.05 & $4.49^{\mathrm{bc}}$ & 0.23 & $0.84^{\mathrm{ab}}$ & 0.04 & $1.97^{\mathrm{c}}$ & 0.03 & 26.69 & 0.88 \\
\hline & 19.0 & $8.26^{\mathrm{a}}$ & 0.19 & $3.29^{\mathrm{c}}$ & 0.06 & $5.08^{\mathrm{cd}}$ & 0.14 & $10.81^{\mathrm{ab}}$ & 0.25 & $5.54^{\mathrm{ab}}$ & 0.13 & $4.95^{\mathrm{ab}}$ & 0.20 & $0.89^{\mathrm{a}}$ & 0.04 & $2.13^{\mathrm{b}}$ & 0.01 & 27.45 & 0.63 \\
\hline & 25.6 & $8.40^{\mathrm{a}}$ & 0.10 & $3.46^{\mathrm{cd}}$ & 0.07 & $4.89^{\mathrm{d}}$ & 0.07 & $11.57^{\mathrm{a}}$ & 0.07 & $5.90^{\mathrm{a}}$ & 0.05 & $5.33^{\mathrm{a}}$ & 0.02 & $0.90^{\mathrm{a}}$ & 0.01 & $2.36^{\mathrm{a}}$ & 0.03 & 28.33 & 0.27 \\
\hline \multicolumn{20}{|c|}{ ANOVA (p-value) } \\
\hline \multicolumn{2}{|l|}{ Lipid } & \multicolumn{2}{|c|}{0.269} & \multicolumn{2}{|c|}{0.041} & \multicolumn{2}{|c|}{0.000} & \multicolumn{2}{|c|}{0.061} & \multicolumn{2}{|c|}{0.000} & \multicolumn{2}{|c|}{0.200} & \multicolumn{2}{|c|}{0.823} & \multicolumn{2}{|c|}{0.000} & \multicolumn{2}{|c|}{0.095} \\
\hline \multicolumn{2}{|c|}{ n-3 LC-PUFA } & \multicolumn{2}{|c|}{0.384} & \multicolumn{2}{|c|}{0.000} & \multicolumn{2}{|c|}{0.000} & \multicolumn{2}{|c|}{0.000} & \multicolumn{2}{|c|}{0.003} & 0.0 & & 0.0 & & 0.0 & & 0.2 & \\
\hline Interac & tion & 0.0 & & 0.00 & & 0.7 & & 0.0 & & 0.0 & & 0.0 & & 0.1 & & 0.0 & & 0.0 & \\
\hline
\end{tabular}

${ }^{*}$ SFA, saturated fatty acids: 14:0, 16:0, 18:0, 20:0; ${ }^{\dagger}$ MUFA, monounsaturated fatty acids: 16:1n-7, 18:1n-9, 20:1n-9; ${ }^{\ddagger} \mathrm{n}-6$ PUFA, n-6 polyunsaturated fatty acids: 18:2n-6, 20:2n-6, 20:4n-6, 22:4n-6; ${ }^{8} \mathrm{n}-3$ PUFA, n-3 polyunsaturated fatty acids: 18:3n-3, EPA, 22:5n-3, DHA; "EPA, 20:5n-3, ${ }^{\text {II } D H A, ~ 22: 6 n-3 ; ~}{ }^{* *}$ TFA, total fatty acid. 
Accepted manuscript

\section{Table 6}

Fatty acid profiles in hepatopancreas of mud crab fed the experimental diets $\left(\mathrm{mg} \mathrm{g}^{-1}\right.$, dry matter) for 8 weeks.

\begin{tabular}{|c|c|c|c|c|c|c|c|c|c|c|c|c|c|c|c|c|c|c|c|}
\hline \multirow{2}{*}{ Lipid } & \multirow{2}{*}{$\begin{array}{l}\mathrm{n}-3 \\
\text { LC-PUFA } \\
\left(\mathrm{mg} \mathrm{g}^{-1}\right)\end{array}$} & \multicolumn{2}{|l|}{$\sum \mathrm{SFA}^{*}$} & \multicolumn{2}{|c|}{$\sum$ MUFA $^{\dagger}$} & \multicolumn{2}{|c|}{$\sum$ n-6 PUFA } & \multicolumn{2}{|c|}{$\sum \mathrm{n}-3 \mathrm{PUFA}^{\S}$} & \multicolumn{2}{|l|}{ EPA" } & \multicolumn{2}{|l|}{ DHA $^{\text {II }}$} & \multicolumn{2}{|c|}{ DHA/EPA } & \multicolumn{2}{|l|}{$n-3 / n-6$} & \multicolumn{2}{|l|}{$\sum \mathrm{TFA}^{* * *}$} \\
\hline & & Mean & SEM & Mean & SEM & Mean & SEM & Mean & SEM & Mean & SEM & Mean & SEM & Mean & SEM & Mean & SEM & Mean & SEM \\
\hline \multirow[t]{3}{*}{ Initial } & & 33.52 & & 25.9 & & 18.1 & & 28.02 & & 11.01 & & 11.81 & & 1.07 & & 1.54 & & 105.54 & \\
\hline & 0.15 & $73.64^{\mathrm{a}}$ & 1.62 & $25.09^{\mathrm{e}}$ & 1.63 & $40.17^{\mathrm{d}}$ & 1.19 & $5.14^{\mathrm{d}}$ & 0.10 & $1.93^{\mathrm{d}}$ & 0.03 & $1.13^{\mathrm{e}}$ & 0.07 & $0.59^{c}$ & 0.06 & $0.13^{\mathrm{f}}$ & 0.01 & $144.04^{\mathrm{d}}$ & 1.23 \\
\hline & 7.4 & $71.50^{\mathrm{ab}}$ & 0.31 & $37.43^{\mathrm{ab}}$ & 0.31 & $57.42^{\mathrm{a}}$ & 0.85 & $25.38^{\mathrm{c}}$ & 0.58 & $10.28^{\mathrm{c}}$ & 0.32 & $10.25^{\mathrm{d}}$ & 0.19 & $1.00^{\mathrm{a}}$ & 0.02 & $0.44^{\mathrm{e}}$ & 0.01 & $191.74^{\mathrm{ab}}$ & 1.34 \\
\hline \multirow[t]{5}{*}{$7 \%$} & 14.8 & $59.64^{\mathrm{bc}}$ & 1.26 & $37.86^{\mathrm{a}}$ & 0.52 & $54.32^{\mathrm{ab}}$ & 1.65 & $40.30^{\mathrm{b}}$ & 1.54 & $16.54^{\mathrm{b}}$ & 1.26 & $18.76^{\mathrm{bc}}$ & 0.25 & $1.15^{\mathrm{a}}$ & 0.14 & $0.74^{\mathrm{c}}$ & 0.01 & $192.12^{\mathrm{ab}}$ & 4.43 \\
\hline & 19.8 & $57.26^{\mathrm{c}}$ & 3.69 & $35.40^{\mathrm{abc}}$ & 0.22 & $53.27^{\mathrm{ab}}$ & 2.15 & $56.10^{\mathrm{a}}$ & 0.78 & $24.17^{\mathrm{a}}$ & 0.35 & $25.46^{\mathrm{a}}$ & 0.38 & $1.05^{\mathrm{a}}$ & 0.00 & $1.06^{\mathrm{b}}$ & 0.04 & $202.03^{\mathrm{a}}$ & 5.87 \\
\hline & 24.9 & $43.83^{\mathrm{d}}$ & 4.21 & $29.02^{\mathrm{de}}$ & 0.82 & $50.93^{\mathrm{abc}}$ & 0.35 & $60.38^{\mathrm{a}}$ & 0.13 & $26.44^{\mathrm{a}}$ & 0.03 & $27.20^{\mathrm{a}}$ & 0.06 & $1.03^{\mathrm{a}}$ & 0.00 & $1.19^{\mathrm{a}}$ & 0.01 & $184.16^{\mathrm{abc}}$ & 4.97 \\
\hline & 0.1 & $69.36^{\mathrm{ab}}$ & 1.73 & $31.35^{\mathrm{cd}}$ & 2.42 & $39.34^{\mathrm{d}}$ & 1.04 & $5.82^{\mathrm{d}}$ & 0.13 & $1.85^{\mathrm{d}}$ & 0.03 & $1.43^{\mathrm{e}}$ & 0.12 & $0.77^{\mathrm{b}}$ & 0.09 & $0.15^{\mathrm{f}}$ & 0.00 & $145.88^{\mathrm{d}}$ & 4.72 \\
\hline & 6.8 & $67.91^{\mathrm{abc}}$ & 0.15 & $32.00^{\mathrm{bcd}}$ & 0.31 & $44.57^{\mathrm{cd}}$ & 1.45 & $22.97^{\mathrm{c}}$ & 1.26 & $9.90^{\mathrm{c}}$ & 0.57 & $10.42^{\mathrm{d}}$ & 0.71 & $1.05^{\mathrm{a}}$ & 0.02 & $0.52^{\mathrm{de}}$ & 0.04 & $167.46^{\mathrm{c}}$ & 1.04 \\
\hline \multirow[t]{3}{*}{$12 \%$} & 13.2 & $69.99^{\mathrm{ab}}$ & 3.01 & $35.93^{\mathrm{abc}}$ & 1.24 & $43.83^{\mathrm{cd}}$ & 1.45 & $26.16^{\mathrm{c}}$ & 0.34 & $11.27^{\mathrm{c}}$ & 0.09 & $12.13^{\mathrm{d}}$ & 0.43 & $1.08^{\mathrm{a}}$ & 0.05 & $0.60^{\mathrm{d}}$ & 0.01 & $175.91^{\mathrm{bc}}$ & 2.36 \\
\hline & 19.0 & $77.69^{\mathrm{a}}$ & 0.47 & $36.26^{\mathrm{abc}}$ & 1.35 & $49.15^{\mathrm{bc}}$ & 2.02 & $37.67^{\mathrm{b}}$ & 1.49 & $16.13^{\mathrm{b}}$ & 0.75 & $17.25^{\mathrm{c}}$ & 0.75 & $1.07^{\mathrm{a}}$ & 0.04 & $0.77^{\mathrm{c}}$ & 0.02 & $200.78^{\mathrm{a}}$ & 5.12 \\
\hline & 25.6 & $78.77^{\mathrm{a}}$ & 3.22 & $37.63^{\mathrm{ab}}$ & 0.23 & $44.12^{\mathrm{cd}}$ & 2.43 & $41.98^{\mathrm{b}}$ & 0.47 & $17.78^{\mathrm{b}}$ & 0.00 & $19.85^{\mathrm{b}}$ & 0.43 & $1.12^{\mathrm{a}}$ & 0.04 & $0.96^{\mathrm{b}}$ & 0.05 & $202.50^{\mathrm{a}}$ & 5.27 \\
\hline \multicolumn{20}{|c|}{ ANOVA (p-value) } \\
\hline \multicolumn{2}{|c|}{ Lipid } & 0.000 & & 0.032 & & 0.000 & & 0.000 & & 0.000 & & 0.000 & & 0.025 & & 0.000 & & 0.109 & \\
\hline \multicolumn{2}{|c|}{ n-3 LC-PUFA } & 0.002 & & 0.000 & & 0.000 & & 0.000 & & 0.000 & & 0.000 & & 0.000 & & 0.000 & & 0.000 & \\
\hline \multicolumn{2}{|c|}{ Interaction } & 0.000 & & 0.000 & & 0.014 & & 0.000 & & 0.000 & & 0.000 & & 0.025 & & 0.000 & & 0.000 & \\
\hline
\end{tabular}

*SFA, saturated fatty acids: 14:0, 16:0, 18:0, 20:0; ${ }^{\dagger}$ MUFA, monounsaturated fatty acids: 16:1n-7, 18:1n-9, 20:1n-9, 22:1n-11; ${ }^{\ddagger} \mathrm{n}-6$ PUFA, n-6 polyunsaturated fatty acids: 18:2n-6, 18:3n-6, 20:2n-6, 20:4n-6, 22:4n-6; ${ }^{\S} \mathrm{n}-3$ PUFA, n-3 polyunsaturated fatty acids: 18:3n-3, 18:4n-3, 20:4n-3,EPA, 22:5n-3, DHA; "IPA, 22:5n-3, ${ }^{\text {Il }}$ DHA, $22: 6 \mathrm{n}-3$; ${ }^{\text {*** }}$ TFA, total fatty acid. 